\title{
La traduction poétique entre la littéralité et l'adaptation (Le cas de « Fleurs du Mal » de Baudelaire.)
}

\author{
Par \\ Magdi Adli Ahmed ALI \\ Maître de conférences à la faculté de langues et de \\ traduction \\ Université d'Al Azhar
}




\section{$\underline{\text { 0. Introduction }}$}

Un des plus grands poètes français du $19^{\text {ème }}$ siècle, Charles Baudelaire a diffusé la version finale de son recueil poétique renommé Les fleurs du Mal en 1857. Son texte ne vise pas le grand public ; le thème traité est spécialisé et exige donc de connaissances particulières pour le rendre en arabe.

Traduire n'est jamais une tâche facile. La traduction n'est pas le remplacement des mots par d'autres mots, mais "c'est reformuler un texte dans une autre langue, en prenant soin de conserver le contenu ${ }^{I} \gg$. C'est à dire rendre le message du texte source en langue cible avec exactitude. De là, le traducteur doit comprendre pour pouvoir atteindre le sens et le réexprimer magistralement. Il est un médiateur entre deux différents mondes, deux cultures, deux civilisations. Il doit être capable de comprendre, de transposer, d'exprimer, avec rigueur et exactitude, le message de la langue source, et de savoir manier, avec rigoureuse précision, sa langue maternelle. C'est une aptitude exigeante pour rendre approximativement le contenu du texte source. "L'objet de la traduction n'est pas la texture dont est faite la langue mais le sens qu'y trouve celui auquel elle

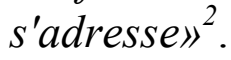

Etre compliquée la tache du traducteur lorsqu'il se livre à rendre les textes littéraires, en particulier les textes poétiques considérés les plus difficiles à cause de ses écarts esthétiques, ainsi ses significations. "La poésie offrait en effet la difficulté

1 ) TATILON, Claude, Traduire: Pour une pédagogie de la traduction, Editions du Gref, Toronto, 1986, p.7

$\left.{ }^{2}\right)$ BRAUNS, Jean, Comprendre pour traduire, perfectionnement linguistique en francais, maison du dictionnaire, Paris, 1981, p. 5

April 2016

65

Vol. 44 
majeure de l'union inséparable du sens et de la sonorité, du signifié et du signifiant ${ }^{l} »$.

Il est presque commun de croire que la traduction de la poésie est impossible et que traduire, c'est toujours trahir. Nombreux auteurs et poètes abondent dans ce sens, tels que Baudelaire, Schotman, Weynen, Maurois et bien d'autres ${ }^{2}$.

Maurice Blanchot paraît rendre la traduction poétique impossible quand il écrit : "Le sens du poème est inséparable de tous les mots, de tous les mouvements, de tous les accents du poème. Il n'existe que dans cet ensemble et il disparaît dès qu'on cherche à le séparer de cette forme qu'il a reçue. Ce que le poème signifie coïncide exactement avec ce qu'il est ${ }^{3} »$. En fait, le traducteur ne pourrait pas prétendre à une parfaite équivalence sémantique, une exacte équivalence sonore. Mais, signalons que nous pouvons ordinairement reconnaître le sens d'un poème indépendamment de sa forme et de ses harmonies. La traduction d'un poème n'est jamais «synonyme » de la source : elle en est tout au plus un analogon ou une approximation.

Les questions que nous allons soulever portent sur la traduction poétique du français vers l'arabe. Cette étude se propose de comparer deux traductions en arabe de quelques poèmes des Fleurs $d u$ Mal de Charles Baudelaire. Nous n'abordons donc que quelques éléments de l'œuvre du poète. Il s'agit d'étayer l'hypothèse selon laquelle la traduction poétique permet de dépasser l'impossibilité de traduire la poésie. Si nous choisissons de nous intéresser à des poèmes de Baudelaire, c'est d'abord par intérêt pour son œuvre et pour la difficulté de sa

1) RICOEUR, Paul, sur la traduction, Bayard, Paris, 2004, p. 12

${ }^{2}$ ) CARY, Edmond, "Traduction et poésie", in: Babel : revue internationale de la traduction, Fédération internationale des traducteurs, 1957, p. 4

${ }^{3}$ ) Cité par Robert Ellrodt, «Comment traduire la poésie ? ", Palimpsestes [En ligne], Hors série | 2006, URL : http://palimpsestes.revues.org/247 
poésie. "Il offre ainsi au lecteur une forme nouvelle qui donne une impression de volupté et de tranquillité, comme une danse régulière ${ }^{l} »$. La traduction de la poésie est une tâche complexe qui ne peut parfaitement être réalisée que par un traducteur et un poète à la fois. C'est la raison pour laquelle nous choisissons la traduction du poète égyptien (Refaat Sallam), car « seul un poète peut traduire la poésie ${ }^{2}$ ». C'est-à-dire il connaît suffisamment le domaine de production des textes qu'il traduit. Certes, il pourrait trouver pour chaque terme et expression l'équivalent propre qui définit l'originalité de la traduction. Egalement, nous choisissons la traduction des poètes libanais (Yohana Al-Tayar et Georgite Al-Tayar), parce qu'ils ont une connaissance pratique et fortement nuancée de la langue française dont tous les éléments sont présents à leur esprit et à leur mémoire au même titre que leur langue maternelle. Ils ont également une solide préparation culturelle et technique qui leur permet d'acquérir rapidement une information suffisante sur les sujets proposés et sur les terminologies spéciales.

Nous avons créé un corpus de quelques poèmes pris dans le texte original tels que : «Bénédiction, Au lecteur, les phares et la vie antérieure» marquant le point de départ de l'analyse comparative entre les diverses traductions en arabe. S'agissant de traductions de poèmes, nous examinons comment les traducteurs traitent les difficultés surgissant quand il fallait transposer les messages du texte original dans le texte traduit et le souci de préserver le style de Baudelaire et les règles de versification.

La littéralité et l'adaptation sont conçues comme deux stratégies différentes et que les traducteurs pratiquent l'une ou

1) MAXIME, Lecture analytique d'Harmonie du soir de Charles Baudelaire, URL : http://lectureanalytique.over-blog.com/article-35707592.html

${ }^{2}$ ) PLACIAL, Claire, "Seul un poète peut traduire la poésie " - Vraiment? URL : http://languesdefeu.hypotheses.org/814

April 2016 
l'autre. De là, cet article n'étudie pas la traduction poétique sous tous ses aspects. Il consiste à mettre en évidence quel procédé, "littéralité et adaptation », est magistralement pratiquée pour rendre une œuvre poétique. L'emprunt, le calque et la traduction mot à mot relèvent de la littéralité, alors que la transposition et la modulation sont considérées comme des manifestations de l'adaptation. À côté des procédés techniques, il existe ce que nous appelons indifféremment procédés ou techniques tout courts (l'ajout et l'omission). Ces procédés semblent coïncider, du moins dans certains cas, avec l'un des procédés techniques. Pour mieux suivre l'analyse, nous présentons d'abord le texte français suivi de deux différentes traductions en arabe.

Nous analysons seulement les vers arborant certaines caractéristiques et certaines difficultés de traduction, offrant aux traducteurs l'occasion d'avoir recours aux procédés, tels que l'ajout, l'omission, la modulation et la transposition.

\section{Traduction des titres}

Le titre occupe une place essentielle et particulière dans le poème. Il résume son thème essentiel, reflète l'intentionnalité du poète, et pourrait représenter la totalité du poème. "Le titre pose dès le début le thème abordél ${ }^{1}$. Il est la fenêtre derrière laquelle nous trouvons le contenu du poème. Il est préférable de rendre le titre après avoir traduit tout le poème, puisque nous ne pourrons pas comprendre le sens du titre sans saisir le contenu du poème. Ceci désigne que nous devons tout d'abord comprendre et traduire le poème afin de rendre équitablement le titre. Parfois, la traduction littérale du titre est refusée, puisqu'elle dénature le sens. "La traduction littérale consiste à traduire la langue source mot à mot, et la traduction libre, à laquelle on recoure

1 ) CELOT, Alberto, La traduction de l'essai poétique : domaine Français Italien. Linguistics. Université de la Sorbonne nouvelle - Paris III, 2014, p. 109 April 2016 
La traduction poétique entre la littéralité et l'adaptation Dr.Magdi Adli Ahmed

pour adapter le texte lorsqu'il présente des termes ou des expressions intraduisibles, des difficultés d'ordre linguistique, ou des connotations différentes. " "

Le titre du poème «bénédiction» a été rendu, tantôt littéral, tantôt libre:

Sallam l'a rendu par : « بركة 》

Al-Tayar a conservé l'arabe et le français pour rendre le titre du poème en arabe : «باركة " et «bénédiction 》.

Il est clair que nous trouvons toujours plusieurs traductions pour un même terme, mais il est impossible que toutes les traductions présentent la même fréquence d'utilisation. Le traducteur devrait s'efforcer de trouver l'équivalent idéal dans la langue d'arrivée pour être adéquat avec la langue de départ. Etudiant les deux traductions, nous observons que tous les deux traducteurs essaient d'approcher, autant que possible, du sens du texte à viser, mais chacun à ses différents procédés. Sallam a utilisé le procédé de la traduction littérale : «بركة 》. C'est-à-dire, il nous donne une traduction telle quelle, alors que le texte comprend une autre chose. En fait, la traduction littérale désigne une traduction mot à mot aboutissant à un texte à la fois correct et idiomatique. Mais, elle n'est acceptable que si la langue d'arrivée garde la même syntaxe, le même sens et le même style que la langue de départ.

En consultant minutieusement la traduction de ce poème, nous constatons qu'il existe un rapport très étroit entre le titre et le contenu du poème, qui traite les réactions d'une mère qui

${ }^{1}$ ) DARBELNET, Jean. Traduction littérale ou traduction libre ? in Meta : journal des traducteurs / Meta: Translators' Journal, vol. 15, n $^{\circ}$ 2, 1970, p. 88-94.

April 2016 
déteste son nouveau-né après avoir passé une nuit aux plaisirs éphémères. Alors, le sens du poème concerne un état de naissance. Dans ce contexte le mot «bénédiction» a le sens de «félicitation».

Ceci nous pousse à dire que la traduction de Sallam est imperfective et inadéquate. Elle pourrait dénaturer le sens visé. Nous devons alors consulter toute la traduction du poème pour en saisir le sens voulu.

Pour la traduction de Al-Tayar, elle a été faite d'une manière transposée, en rendant le nom simple «bénédiction» par un «Masdar» nom d'action « مباركة » parce qu'il a décidé que ce mot pourrait justement rendre le sens et le thème principal du poème plus expressivement. Signalons que la transposition consiste à changer la catégorie grammaticale d'un mot ou d'un groupe de mots sans changer le sens du message. Il a bien compris l'intention de l'écrivain. Nous devons alors annoncer que la traduction est adéquate et satisfaisante, puisque le sens du titre est compatible avec le contenu du poème. Nous préférons alors la traduction d'Al-Tayyar " مباركة 》qui bien conserve l'idée de la langue source.

Le titre du poème «Au lecteur » a été rendu littéralement : Les deux traducteurs ont opté les termes : "إلى القارئ Mais, Al-Tayar a conservé l'arabe et le français pour le titre du poème en arabe : " et «Au lecteur 》.

Nous remarquons que la traduction de ce titre était très facile. Chacun de deux traducteurs l'a littéralement et magistralement rendu en employant la traduction littérale. En fait ce poème est considéré comme une dédicace et une introduction puisque toutes les tentatives de Baudelaire d'écrire une 
introduction à son recueil de poésies ont échoué puisqu'il voit que la poésie n'est pas expliquée et interprétée. Au lieu de commencer son recueil par une introduction, il a préféré de mettre en tête le poème " Au lecteur » qui exprime sa révolte et le mépris de tout ce qui l'entoure. Les deux traducteurs ont bien cerné l'intention de l'écrivain. C'est pourquoi nous signalons que la traduction est adéquate et systématique.

Quant au poème "Les phares », il est toujours la pièce 6 de la première partie intitulée "Spleen et idéal ». Les thèmes de Baudelaire sont la mélancolie et l'idéal : il veut échapper à la dépression par l'écriture sur l'idéal, le vin, la mort. Baudelaire cherche à éveiller des sensations qui correspondent à celles que suscite l'oeuvre de chaque peintre évoqué. Ces artistes qui interprètent le langage mystérieux de la nature et qui traduisent les inquiétudes humaines sont « les phares » qui éclairent la route des Hommes ${ }^{1}$.

La comparaison entre les deux traductions, nous montre alors quel procédé les traducteurs ont utilisé pour ne pas déplacer le sens. Pour le titre du poème "Les Phares », Sallam l'a traduit par «الفنارات», tandis que Al-Tayar l'a traduit par « المنارات, mot utilisé uniquement par les arabes. Mais, Al-Tayar a conservé le mot français «les Phares" à côté de l'arabe pour le titre du poème. Cette traduction " المنارات donne pleine satisfaction. Il s'agit en fait d'une acception du terme employé par les locuteurs arabes en raison de la polysémie de la langue arabe. Baudelaire rend hommage à plusieurs artistes en les citant et en notant quelques mots résumant leur art. Il définit un point commun à tous : l'exclamation des sentiments, qu'il semble donner en

$\begin{array}{lcl}\text { 1) http://www.bacfrancais.com/bac francais/68-commentaire-baudelaire-les- } & \\ \text { phares.php } & 71 & \text { Vol. } 44 \\ \text { April } 2016 & 71\end{array}$ 
offrande au Ciel ${ }^{1}$. C'est pourquoi nous voyons que la version d'Al-Tayar est adéquate et pertinente.

\section{La littéralité}

La traduction est un travail qui demande équilibre et harmonie, puisqu'il pose le problème de la distance que le traducteur doit garder par rapport au texte à traduire : ne pas trop respirer l'air qu'il respire, ne pas l'aider plus à respirer artificiellement. Garder l'effet d'un texte à travers la traduction suppose que le traducteur doit être en harmonie parfaite avec les deux textes ${ }^{2}$.

Le mot à mot, le calque et l'emprunt sont des caractéristiques essentielles de la littéralité. Les traducteurs y ont énormément recours. La littéralité est donc présente sous différentes formes.

\subsection{Traduction mot à mot}

La traduction mot à mot consiste en un transfert littéralement d'un énoncé; elle assure les mêmes fonctions syntaxiques et sont placés dans le même ordre : "Ce procédé est un transfert terme à terme de la phrase de départ qui résulte d'une convergence lexico-grammaticale: hétéronymie directe, règles d'agencement identiques même ordre séquentiel des hétéronymes ${ }^{3} »$.

1) http://analyses-litteraires.com/analyses/viewtopic.php? $\mathrm{f}=364 \& \mathrm{t}=589 \&$ start $=1 \& \mathrm{st}=\mathbf{0}$ \&sk=t\&sd = a \&sid=9ade8319c6bdd2f9ca2a80135ce20427\&view=print

2 ) MICHEL, Jacqueline, les enjeux de la traduction littéraires, textes réunis, Publiesud, Paris 2004, p. 27

${ }^{3}$ ) CRISTA Teodora, stratégies de la traduction, Editura Fundaţiei România de Mâine, Bucureşti, 2007, p. 112 
Lederer, de son côté, insiste sur le fait que «La traduction mot à mot, utilisée essentiellement en traduction interlinéaire, sert à mettre en évidence les structures de la langue de départ ${ }^{l} »$.

Le traducteur doit retransmettre le contenu à partir des idées et des intentions transportées par le texte source " On connaît le problème des faux amis; le calque est leur proche parent et si le traducteur expérimenté ne tombe pas dans le piège du faux sens grossier, il lui arrive d'appliquer une règle très simple: toujours douter de la stricte identité conceptuelle de formes semblables dans deux langues ${ }^{2} »$.

Observons à présent la traduction de ce passage du poème «Au Lecteur» :

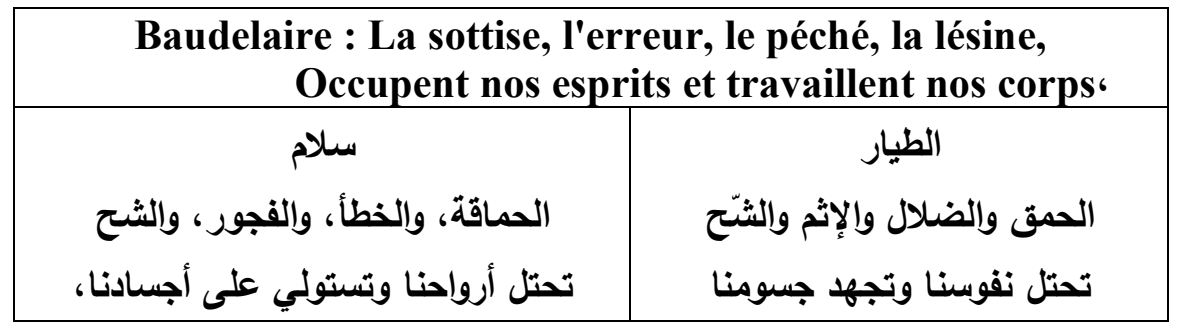

Comme nous le voyons par les exemples ci-dessus la traduction mot à mot est un énoncé équivalent. Al-Tayar a souvent recours aux vers libres, propres à son style qui se différencie des caractéristiques du style de Baudelaire, il présente un style libre, innovateur, sans règles établies, tandis que Sallam préfère perpétuellement de préserver les caractéristiques des poèmes originaux conservant le plan des strophes utilisé par Baudelaire.

1 ) LEDERER, M. La traduction aujourd'hui, le modèle interprétatif, Hachette, Paris, 1994, p. 217 
Les traducteurs optent pour une traduction mot à mot : ils remplacent des signifiants sources par des signifiants cibles, ayant la signification la plus proche. Les termes présents dans le français sont transformés par des mots correspondants dans l'arabe de manière assez aisée. Sallam a souvent recours à la traduction mot à mot en rendant le nom "la sottise » par son équivalent « الحمق «, tandis qu'Al-Tayar choisit l'infinitif

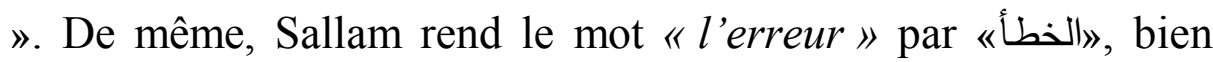
qu'Al-Tayar choisit le terme " الضـلد q qui est plus harmonieuse avec le mot suivant "le péché ", lequel il traduit mot à mot par 《الإثم الفجور 《. Mais nous préférons un autre terme "الخطيئة 》. Chacun a choisi les termes qu'il estime plus adoptés à la langue cible.

Pour connaitre le sens d'un mot ou d'une expression, le traducteur fait davantage appel au dictionnaire monolingue qu'il trouve plus précis et plus complet pour la compréhension des unités à traduire. En revanche, lorsqu'il consulte un dictionnaire bilingue, il le fait savoir comment nous traduisons tel ou tel mot ou expression. Cela ne signifie pas toujours qu'il ignore le sens de l'unité en question mais il est à la recherche de la meilleure façon de la traduction par rapport au contexte ${ }^{1}$.

Dans le syntagme verbal «travaillent nos corps », le verbe " travailler » est transitif. Il a alors le sens : Tourmenter, causer de la peine ${ }^{2}$, traduit par "يعذب - يؤلم - Mais, Sallam l'a rendu par

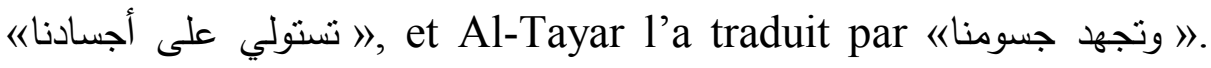
C'est une traduction un peu proche. Nous pourrons également

1 ) GUIDERE, Mathieu, La traduction arabe, Méthodes et applications, ellipses, Paris, 2005, p. 90

$\left.{ }^{2}\right)$ https://fr.wiktionary.org/wiki/travailler 
La traduction poétique entre la littéralité et l'adaptation Dr.Magdi Adli Ahmed

considérer que cette traduction est presque interprétative qui " consiste à transférer des sens identiques d'une langue à l'autre dans l'équivalence des formes ${ }^{1} »$. Dans ce type de traduction, le traducteur prend conscience des sens d'un texte puis le réactualise en un nouveau texte dans une langue différente.

Un autre exemple de traduction littérale est fourni par cet autre passage du poème " Bénédiction » :

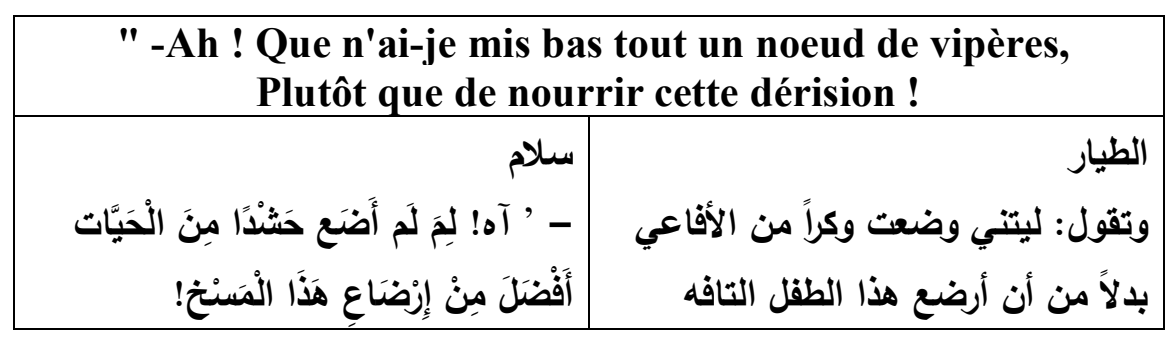

Salam nous présente un exemple d'une traduction littérale sans grandes difficultés mais avec quelques adaptations. Il conserve dans sa version les caractéristiques du vers baudelairien dans sa forme et son contenu.

Remarquons que les deux traducteurs ont omis les termes "bas tout" sans la perte de la compréhension du message source. Dans le même vers nous y voyons un ajout accepté à propos de la traduction d'Al-Tayar, qui a ajouté le verbe (يقول) en tête de sa traduction pour rapprocher, autant que possible, de la langue de départ, ainsi pour rendre le sens plus claire et donner le ton à la traduction.

Dans le deuxième vers, Salam a traduit le terme «dérision» par (الََْنْن qui n'a pas la même connotation. Le vocable

1 ) LEDERER, M. La traduction aujourd'hui, op.cit, p. 216 April 2016 
«dérision» signifie : «Moquerie souvent accompagnée de mépris ${ }^{1}$ ou ce qui est dérisoire, insignifiant $\rangle^{2}$. Le mot (الَْسنَخ) a le sens de :

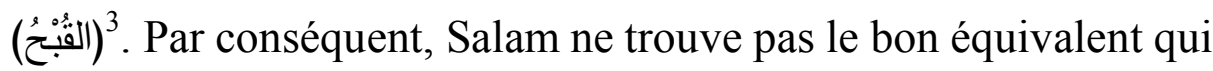
rend le message du texte source, car le mot «dérision», dans ce

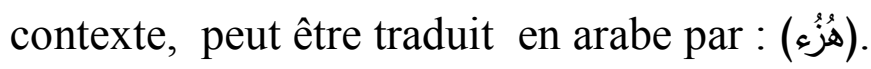

Dans la version Al-Tayar, le mot «dérision» a été magistralement traduit par le syntagme nominal : الطفل الثافه) enfant insignifiant). C'est une expression vulgaire et très fréquente en arabe. Elle provoque un étoffement en donnant plus d'harmonie à la traduction. L'étoffement est le renforcement d'un mot qui ne se suffit pas à lui-même et qui a besoin d'être épaule par d'autres. Le traducteur doit nous raconter quelque chose en partant d'un texte et en l'imitant le plus possible formellement. Al-Tayar, dans sa version, est le plus proche du sens du mot 《dérision» : (هُزُْء) qui a le sens de (الطفل التافة).

En général, Sallam a essayé de confirmer la souplesse de la construction formelle du poème en arabe, ce qui a conduit parfois à la possibilité de reproduire la strophe du poème source, mais sans rime.

\subsection{Le calque}

Il consiste à emprunter à la langue étrangère la structure mais en traduisant littéralement les éléments qui la composent. Le calque est parfois possible mais très rarement. Il aboutit le plus souvent à une traduction inacceptable. Le calque lexical consiste à se laisser piéger par les faux amis.

1) http://fr.wiktionary.org/wiki/dérision

$\left.{ }^{2}\right)$ http://www.larousse.fr/dictionnaires/francais/d\% C3\%A9rision/24015

3 ) http://www.almaany.com/ar/dict/ar-ar/\%D9\%85\%D8\%B3\%D8\%AE/

April 2016 
Chaque fois que la littéralité est impossible, il faut recourir à l'adaptation à l'aide de procédés particuliers. Ce procédé consiste en une traduction littérale des éléments constitutifs d'une séquence termes ou en un transfert sémantique. "Le calque résulte de la traduction littérale des éléments constitutifs d'une lexie complexe ${ }^{l} »$. Le texte arabe emploie quelques calques français.

Citons quelques exemples tirés du poème «Bénédiction » :

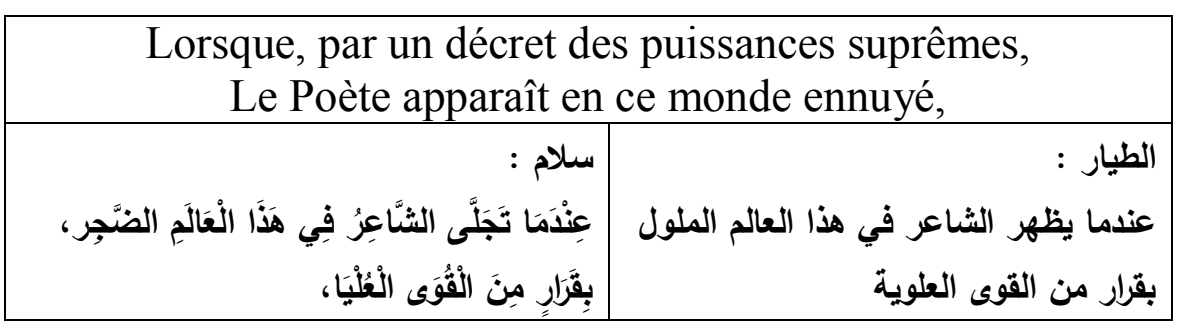

Nous trouvons ci-dessus un exemple de transcodage lexical : par un décret des puissances suprêmes.

Pour qui comprend le français, ce passage est immédiatement clair ; le seul problème est un problème d'expression puisque la déverbalisation est insuffisante.

$$
\begin{aligned}
& \text { Saقََرارِ مِنَ الْقُوَى الْعُلَيْا، : Sallam } \\
& \text { AL-tayar : بقرار من القوى العلوية : }
\end{aligned}
$$

Pour exprimer de façon adéquate, il doit retrouver la réalité cachée derrière les mots, c'est-à-dire "une déverbalisation complète, une prise de conscience de ce dont il s'agissait ${ }^{2} »$.

1) CRISTA Teodora, stratégies de la traduction, op.cit, p. 103

${ }^{2}$ ) LEDERER, M. La traduction aujourd'hui, op.cit, p. 114

April 2016 
Les deux traducteurs se sont alignés sur le calque. Ils semblent ne pas avoir eu besoin de créer une expression propre pour cette notion; ils se sont contentés de l'emprunter littéralement au français. En fait, le calque est une source importante permettant de pénétrer de significations lexicales françaises en arabe. Sous l'effet de ce procédé, les significations initiales des mots arabes se trouvent enrichies d'une couche sémantique supplémentaire.

Dans ces vers, comme nous pouvons le remarquer, la tentative de la littéralité a conduit tout naturellement, et de façon inconsciente, à nuire au sens. Les deux traducteurs ont littéralement rendu le syntagme nominal "par un décret des puissances suprêmes»par «بقرار من القوى العليا (العلوية) ". Cette littéralité s'est révélée comme une trahison, puisque nous encourions dénaturer le sens. Par conséquent, pour rendre l'idée du texte source, il est nécessaire de traduire aussi fidèlement et précisément que possible. Nous avons alors recours à la traduction interprétative et retombons sur une expression telle que : (بعد إرادة الهة), qui, à notre avis, correspondrait à une manière plus claire d'exprimer l'idée de la langue source. Nous ne prenons pas alors le risque de trahir le sens.

La littéralité de la traduction rend, quelquefois, certains passages déroutants pour le lecteur. Certains passages de la traduction de Sallam et de Tayar sont difficiles à comprendre en raison de leur syntaxe ou de tournures inhabituelles, comme cette phrase extraite de Bénédiction:

\begin{tabular}{|c|c|}
\hline $\begin{array}{c}\text { Baudelaire : «Ah ! que n'ai-je mis bas tout un nœud de } \\
\text { vipères, }\end{array}$ \\
Plutôt que de nourrir cette dérision ! \\
\hline سلام & $:$ الطيار \\
\hline
\end{tabular}


La traduction poétique entre la littéralité et l'adaptation Dr.Magdi Adli Ahmed

\begin{tabular}{|c|c|}
\hline 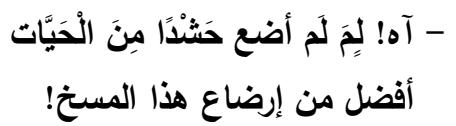 & 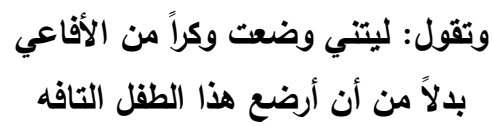 \\
\hline
\end{tabular}

Salam nous présente un exemple d'une traduction littérale sans grandes difficultés mais avec quelques adaptations. Il conserve dans sa version les caractéristiques du vers baudelairien dans sa forme et son contenu.

Dans certains cas, le calque apparaît dans la langue source et il est retraduit tel quel dans la langue d' arrivée. Le texte arabe nous apprend que c'est une traduction entièrement littérale. Pour l'expression, " un nøud de vipères », Sallam l'a rendue par (حَتْدَاً مِنَ الْحَيَّات). Al-Tayar a opté le syntagme (وكراً من الأفاعي). La syntaxe des deux langues est tout à fait similaire: chaque mot occupe la même place et la même fonction grammaticale. Le rythme de la langue du départ est respecté. Comme cette expression signifie : amas formé par les corps entrelacés de plusieurs vipères $^{l}$ ou nid de vipères ${ }^{2}$, nous voyons que la version d'Al-Tayar est la plus proche. Mais nous préférons l'omission du terme «nœud», ainsi le verbe «nourrir » en raison d'expressivité. Ayant recours à la traduction interprétative, nous pourrions rendre ces vers par : (كنت أفضل أن ألذَ حية خيرا لي من هذا الطفل التافه) qui s'adapte le mieux au texte français.

Observons à présent la traduction de ce vers extrait du poème « bénédiction » :

1)

http://dictionnaire.reverso.net/francais-

definition/noeud \%20de\%20vip\%C3\%A8res

${ }^{2}$ ) http://www.notrefamille.com/dictionnaire/expression/vipere

April 2016

79

Vol. 44 


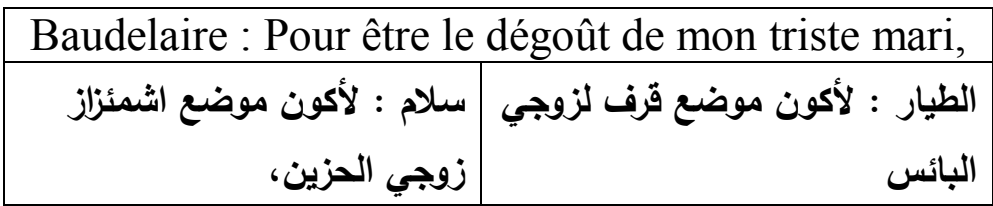

Cette traduction est, elle aussi, très proche du texte original, au point que le texte semble calqué du français, à quelque exception près : les deux traducteurs ajoutent le terme inexistant dans le texte source. Pour le mot "dégoût» chacun choisit un terme différent. Al-Tayar opte le terme vulgaire (قرف), alors que Sallam choisit magistralement le mot (اشمئزاز). Ce calque et cet ajout donnent lieu à une phrase habituelle en arabe.

Notons un autre calque français tiré du poème «bénédiction » :

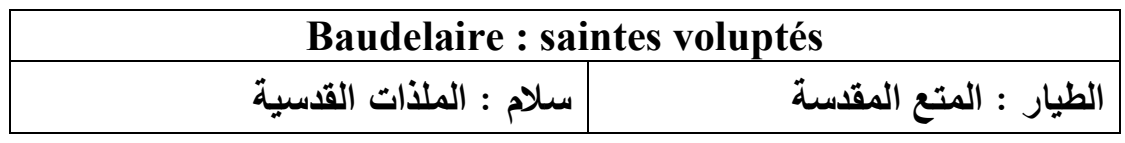

L'expression du texte source "saintes voluptés " est traduite par les deux traducteurs à l'aide du calque. Ils l'ont littéralement rendue. Cependant, il existe certaines différences sémantiques. Chacun de deux traducteurs a opté un équivalent différent. Pour le terme " saintes », Sallam a choisi l'équivalent

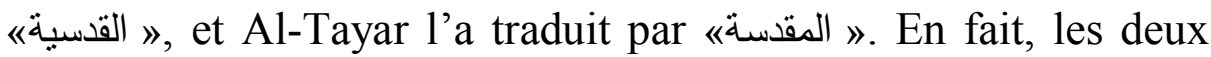
sont presque synonymes. Le mot قدسي " rendu en français par "saint» indique le degré extrême d'un sentiment de réaction contre quelque chose, quelqu'un ${ }^{1}$. Le terme " مقس traduit en français par «sacré » se dit des sentiments de crainte et de

1 ) http://www.larousse.fr/dictionnaires/francais/saint sainte/70547 April 2016 
La traduction poétique entre la littéralité et l'adaptation Dr.Magdi Adli Ahmed

respect inspirés par les choses qui sont l'objet d'une révérence religieuse ${ }^{1}$. Etant donné que cette expression n'existe pas en arabe, nous signalons que le calque est un procédé qui contribue à l'enrichissement de la langue d' arrivée. C'est une source importante de pénétration en arabe de significations lexicales françaises. Ajoutons également que le mot «قدسة " est هذه أمور مقدة " couramment employé en arabe, à titre d'exemple ه دي حاجات مقدس عندي " ou De là, la meilleure traduction est celle d'Al-Tayar.

Un autre exemple tiré du poème «bénédiction »:

\begin{tabular}{|r|r|}
\hline \multicolumn{2}{|c|}{ Baudelaire : cet arbre misérable } \\
\hline الطيار : هذه الثجرة : هذه الثجرة & \\
البائسة & \\
\hline
\end{tabular}

Dans cet exemple, les deux traducteurs adoptent de distinctes attitudes envers la traduction de cette locution. L'expression «cet arbre misérable» n'existe pas dans la langue cible. Ayant recours au calque, Sallam l'a littéralement rendue. Tandis qu'Al-Tayar a recours à l'omission de l'adjectif «misérable - البائسة》. Le différent procédé employé par Al-Tayar ne modifie pas cependant le sens général du texte source, il rend la phrase plus appropriée et accessible.

Citons également ce vers pris du poème «bénédiction » :

Baudelaire : tresser ma couronne mystique

http://www.larousse.fr/dictionnaires/francais/sacr\%C3\%A9/70445?q=sacr\%C3\%A9\# 69689

April 2016 


\begin{tabular}{|c|c|}
\hline سلام : أضفر إكليلي & الطيار : صناعة تاجي \\
\hline
\end{tabular}

Avec certaines différences sémantiques, les traducteurs ont calqué cette phrase. Nous pouvons trouver plusieurs procédés de la traduction utilisés pour transmettre cette phrase en arabe. Pour le verbe «tresser », Sallam a recours à la modulation en rendant l'infinitif par l'inaccompli en arabe « أضفر», tandis qu'Al-Tayar le rend par un nom choisissant un mot voisin صناعة" 》. Pour le terme «ma couronne», les traducteurs ont opté deux mots synonymes. Sallam a choisit le terme "إكليلي ", alors qu'Al-Tayar a adopté le mot "ناجي. De plus, Al-Tayar a eu recours au fauxsens en rendant le terme «mystique» par «الرمزي. En effet, il comprend le sens du mot, mais il n'arrive pas à comprendre l'idée que le poète veut dire. Par contre, du point de vue sémantique, la traduction de Sallam est la meilleure, car il a trouvé l'équivalent approprié «الروحي ».

Certains calques sont figés et enregistrés dans les dictionnaires

\begin{tabular}{|r|r|}
\hline Baudelaire : chemin de la croix \\
\hline الطيار: درب : الآلام \\
\hline
\end{tabular}

Il existe quelques différences entre les deux traductions. Cherchant dans les dictionnaires de la langue, nous trouvons que l'expression figée « chemin de croix » rappelle celui parcouru par 
La traduction poétique entre la littéralité et l'adaptation Dr.Magdi Adli Ahmed

Jésus portant sa croix dans les heures qui ont précédé sa mort ${ }^{1}$. Nous appelons aussi "stations ${ }^{2}$ ». Les dictionnaires bilingues rendent cette locution en arabe par «هراحل الصلب». Dans cet exemple, les traducteurs adoptent de distinctes attitudes envers sa traduction. Dans la traduction effectuée par Sallam, la phrase du texte original est littéralement traduite à l'aide du calque « طريق 》. Le calque employé par Sallam est remplacé par une traduction interprétative dans la version d'Al-Tayar 《دب الآلام 》 در. Sa traduction ne correspond pas précisément au texte original.

Nous pouvons enfin signaler que l'emploi du calque est plus fréquent chez Sallam que chez Al-Tayar.

\section{$\underline{\text { 2.3. L' emprunt }}$}

L'emprunt est le procédé par lequel nous rendons en langue d'arrivée un mot, tel quel, de la langue de départ. Il consiste à intégrer un élément d'une langue dans l'autre. Il peut combler une lacune de la langue d'arrivée. Il peut permettre aussi de conserver la couleur locale d'un texte original et établir un rapport étroit entre les deux langues.

Les traducteurs ont également recours à emprunter des mots tels quels à la langue de départ dans la langue cible, soit pour offrir une part de dépaysement, soit pour combler une lacune lexicale, mais sans pour autant nuire à la compréhension

1 ) Signalons également que dans chaque église, un ensemble de quatorze tableaux est appelé "chemin de croix". Chaque année, pendant la Semaine sainte, en s'arrêtant devant chacun d'eux, les chrétiens se remémorent les derniers moments de la vie de Jésus.

URL : http://www.croire.com/Definitions/Ecole-de-priere/Chemin-de-croix 2) http://www.larousse.fr/dictionnaires/francais/chemin/15074/locution?q=chemin+de+cr oix\#152635;

April 2016 
globale du texte. "C'est un procédé auquel le traducteur fait appel: - si un terme équivalent, qui recouvre d'une manière exacte la réalité évoquée, n'existe pas dans la langue cible; - si le traducteur veut replacer le texte d'arrivée dans le contexte caractéristique du texte de départ ${ }^{1} \gg$.

L'emprunt se présente sous la forme d'une ressemblance phonématique. C'est-à-dire les mots empruntés gardent toujours leur forme et leur prononciation originale, mais ils pourraient subir de certaines modifications pour s'adapter au système arabe. L'emprunt est un fait social. Car il reflète, culturellement, l'influence d'une société sur une autre.

Etant donné que l'emprunt est une «action de prendre à un auteur, à un artiste un élément de son cuvre pour inclure dans la sienne, cet élément, interaction d'une langue d'un mot étranger ${ }^{2} »$, le traducteur a emprunté au français quelques termes n'ayant pas d'équivalent dans la langue cible.

Prenons cet exemple tiré du poème "la vie antérieure », traduit par Sallam : basaltiques

Baudelaire : rendaient pareils, le soir, aux grottes

Sallam

$$
\text { تجعلها ، في المساء ، شبيهة بالكهوف البازلتية : }
$$

Le mot (البازلتية) en arabe est emprunté au mot français «basaltiques ». Sallam dans sa traduction respecte cet emprunt qui est, de plus, devenu couramment utilisé en arabe. Il est indispensable en rendant l'emprunt en arabe de garder la prononciation française. L'adjectif emprunté reste en général tel

1 ) CRISTA Teodora, stratégies de la traduction, op.cit, p. 110

${ }^{2}$ ) Dictionnaire de Langue Française, encyclopédie et noms propres, Hachette, ,Paris, $1987, \mathrm{p.850}$.

April 2016 
La traduction poétique entre la littéralité et l'adaptation Dr.Magdi Adli Ahmed

quel, garde la prononciation française et se termine par la syllabe 《 ب.

Prenons cet autre exemple du poème «les phares »:

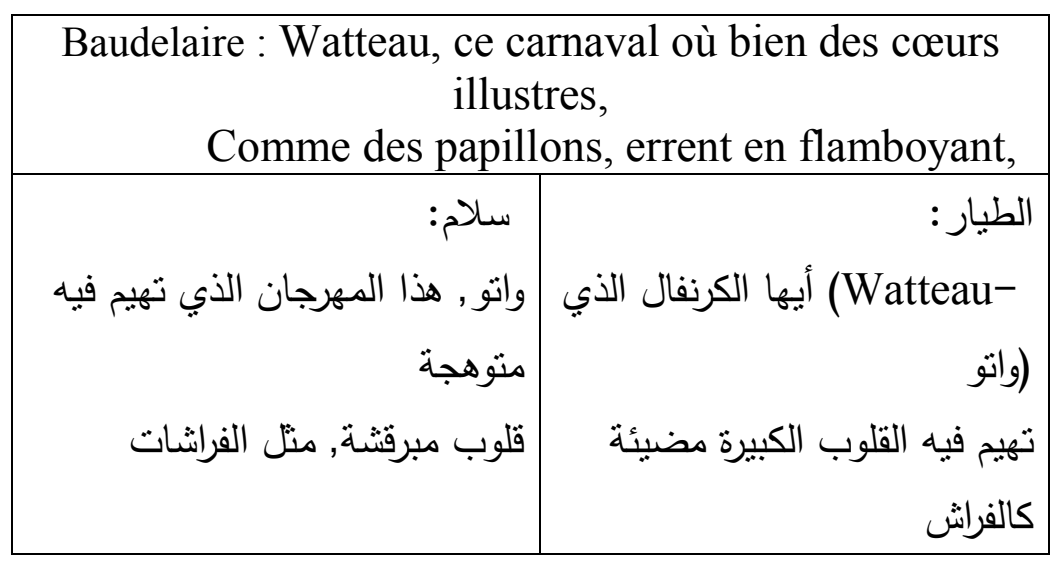

Le texte français contient un terme comme "carnaval», pour lequel, d'après Al-Tayar, la langue arabe n'a pas de terme équivalent. Plutôt que de recourir à une définition ou à une explication, il utilise purement et simplement le terme de la langue française qui devient alors un emprunt. Le mot «carnaval » est alors transmis tel quel dans la traduction d'AlTayar et se présente sous la forme d'une ressemblance phonématique « الكرنفال ». Ce procédé a l'avantage d'enrichir la langue arabe. L'évocation du mot français «carnaval » dans une traduction arabe "ككرنفال n'est pas susceptible de perturber Sallam qui l'assimile spontanément au mot "هرجان". Le lecteur doit, en effet, découvrir les choses par lui-même et même s'il comprend les détails avec un certain décalage par rapport au lecteur original. Nous voyons quand même que les deux traductions sont appropriées et pertinentes. 
Citons également cet exemple pris du poème «bénédiction »:

\begin{tabular}{|r|r|}
\hline \multicolumn{2}{|c|}{ Baudelaire : la douleur est la noblesse } \\
unique \\
\hline الطيار : الألم هو الشرف العذاب هو النبل & الفريد \\
\hline
\end{tabular}

Le mot "noblesse » est un mot composé de "noble + esse » et signifie caractère de quelqu'un, de quelque chose qui est grand, élevé ${ }^{1}$. Pour rendre ce terme en arabe, les traducteurs observent les mêmes lois que dans l'exemple précédent. Sallam transmit le mot à l'aide de l'emprunt « نبل 》. En fait, les termes 《noblesse » et 《نبل ont la même racine 《nobl». Al-Tayar essaie de trouver l'équivalent le plus proche dans la langue arabe en rendant ce terme par « الشرف ». Nous voyons que le traducteur a eu tort parce qu'il a choisi un mot relativement loin et inapproprié.

Citons également cet exemple du poème «les Phares » :

\begin{tabular}{|c|c|}
\hline \multicolumn{2}{|c|}{$\begin{array}{l}\text { Baudelaire : Michel-Ange, lieu vague où l'on voit des } \\
\text { hercules }\end{array}$} \\
\hline سلام : مايكل أنجلو ، & Michel-- الطيار : (مايكل اونج \\
\hline مكان ضبابي نرى فيه & (Ange \\
\hline شخوص هرقل & يـها المكان الغامض الذي تختلط \\
\hline & فيه العمالقة \\
\hline
\end{tabular}

1 ) http://www.larousse.fr/dictionnaires/francais/noblesse/54726 
Pour le mot «Hercules », Sallam le considère comme un nom propre et le rend par son équivalent en arabe "هرقل》, il est l'un des héros les plus vénérés de la Grèce antique. Ce nom propre vient «Du latin Hercules, et héros de la littérature latine $^{l} »$, connu par sa force et ses travaux. Tandis qu'Al-Tayar le traduit comme un commun par 《العمالقة " " Familièrement, homme fort et robuste. C'est un Hercule ${ }^{2} »$. En fait, les deux traductions sont acceptées et pertinentes parce que le terme 《Hercules 》 a deux équivalents en arabe 《هرقل et 《همالقة " العما 》.

En général, chacune de ces traductions a ses particularités raffinées qui le rendent merveilleuse. Salam suit souvent les traces de Baudelaire. Il garde toujours la même forme, et conserve également les règles de la ponctuation. Mais, signalons que le traducteur ne doit jamais se contenter de restituer littéralement et librement la poésie, parce que "la traduction de poésie n'informe pas, qu'elle recrée, ou réécrit, tout en restant comme le disait Mounin un art, mais un art fondé sur une science ${ }^{3} \gg$.

\section{L'adaptation}

L'adaptation constitue une conduite à valeur dynamique, considérée depuis Vinay et Darbelnet comme un procédé de traduction; c'est-à-dire des mécanismes que le traducteur « met en ouvre afin de rétablir l'équilibre avec son milieu ${ }^{4} »$. Elle est «le

\footnotetext{
1) https://fr.wiktionary.org/wiki/Hercule

$\left.{ }^{2}\right)$ http://dicocitations.lemonde.fr/definition littre/12960/Hercule.php

3 ) LUNGU BADEA, Georgiana, Sur la fragilité des signes. Diverses questions sur la traduction de poésie,

URL :

http://www.uab.ro/reviste recunoscute/philologica/philologica 2005 tom2/39.doc $\left.{ }^{4}\right)$ LEDERER, Marianne, études traductologiques, textes réunis, lettres moderne minard, Paris, 1990, p. 218

April 2016 
processus de modification par lequel le traducteur se conforme et ajuste son comportement aux conditions que le milieu impose à sa pratique ${ }^{l} \gg$.

Ladmiral définit l'adaptation en disant que " l'adaptation désigne au moins un procédé de traduction qu'elle indique les limites : c'est le cas limite, pessimiste, de la quai-intraduisbilité, là où la réalité à laquelle se réfère le message source n'existe pas pour la culture cible ${ }^{2} »$.

Le traducteur doit s'intéresser à la totalité du texte source car la littéralité pourrait déformer le message délivré aux récepteurs «Parfois, la méthode littérale aboutit à des résultats qui ne rendent pas l'original ${ }^{3} »$.

L'adaptation commence quand le traducteur démantèle la construction du vers pour en supprimer ou en ajouter plusieurs termes, au risque d'entraîner des incohérences. Pour adapter le texte au contexte culturel de la langue cible, les traducteurs ont recours à divers procédés, tels que la modulation et la transposition ....

\subsection{La transposition}

Elle consiste à «remplacer une partie du discours par une autre, sans changer le sens du message ${ }^{4} »$. C' est-à-dire nous remplaçons une catégorie grammaticale par une autre sans modifier le sens de 1' énoncé. Son emploi dans le passage du

1) Idem

2 ) LADMIRAL, J. R., Traduire : Théorèmes pour la traduction, Gallimard, Paris, 1994, p. 20

${ }^{3}$ ) HURTADO, Albir Amparo, La notion de fidélité en traduction, Didier Erudition, Paris, 1990, p.138.

${ }^{4}$ ) VINAY, J. P. et DARBELNET J., La stylistique comparée du français et de l'anglais, Didier, Paris,

2009, p. 50.

April 2016

88

Vol. 44 
La traduction poétique entre la littéralité et l'adaptation Dr.Magdi Adli Ahmed

français en arabe est très répandu et fréquent. En fait, il existe des transpositions portant sur de différentes formes : verbe, nom, adjectif, adverbe et préposition. Etc.

Quelques exemples de transpositions fréquentes

\section{- Adjectif $>$ participe}

Observons la traduction de ce vers du poème «Bénédiction»:

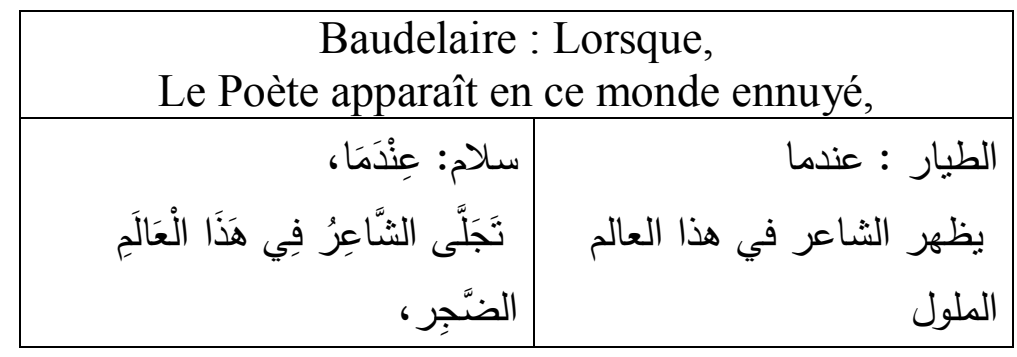

Salam a recours à la transposition en rendant le participe passé «ennuyé», employé comme adjectif, par le participe présent (الضَّدِرِ), différemment Al-Tayar qui a choisi la voie de traduction littérale en traduisant le participe passé par son équivalent en arabe (الملول). Il s'agit donc d'une transposition (adjectif > participe). Il est clair que nous trouvons toujours plusieurs traductions pour un même terme, mais il est impossible que toutes les traductions présentent la même fréquence d'utilisation. Nous voyons que les deux traductions sont incompréhensibles, et non fréquente en arabe. Nous préférons les termes (مل-مزعج) ayant un sens pertinent.

- Adjectif $>$ verbe

Voici un exemple tiré du poème " les Phares » : 


\begin{tabular}{|c|c|}
\hline \multicolumn{2}{|c|}{$\begin{array}{l}\text { Baudelaire : Delacroix, lac de sang hanté des mauvais } \\
\text { anges, }\end{array}$} \\
\hline سلام : ديالاكروا ، بحيرة & الطيار : (De Lacroix-دي لاكروا) يا \\
\hline دماء تغشاها ملائكة شريرة & بحيرة من دم يسكنها ملائكة أشرار \\
\hline
\end{tabular}

Ayant recours à la transposition, les traducteurs font un excellent passage de la langue française dans la langue arabe tout en faisant attention à ne pas perturber le texte original. Par exemple, ils traduisent fidèlement et précisément le participe passé, employé comme adjectif, " hanté » par un verbe conjugué à l'inaccompli "تغناها- يسكنها 》. Il s'agit donc d'une transposition (adjectif $>$ verbe). Cette traduction reste tout à fait compréhensible pour le lecteur arabe : elle est adéquate et précise.

- Syntagme prépositionnel $>$ locution verbale

Voyons cet exemple :

\begin{tabular}{|c|c|}
\hline \multicolumn{2}{|c|}{ Ange, } \\
\hline سلام: لكن، تحت حماية ملاك & الطيار : لكن ملاكاً خفيا يبسط \\
\hline خفية، & حمايته \\
\hline
\end{tabular}

Al-Tayar a recours à la transposition en traduisant un syntagme prépositionnel "sous la tutelle» par une locution verbale (يبسط حمايته). Il s'agit donc d'une transposition (syntagme prépositionnel $>$ locution verbale). Sallam nous offre une belle traduction tout en gardant en général les standards du texte original à travers la traduction littérale; il a suivi la même structure de la phrase française qui a des équivalences avec la langue arabe. 
La traduction poétique entre la littéralité et l'adaptation Dr.Magdi Adli Ahmed

Nous remarquons que la transposition est très fréquente dans le passage du français vers l'arabe. Tous les exemples cités sont soumis aux règles de la transposition. De là, il existe un changement essentiel entre les unités linguistiques en français et en arabe.

\section{2. la modulation}

Elle s'agit d'un changement de point de vue sans modifier nécessairement le message de l'énoncé source. Vinay et Darbelnet signale que "la modulation est une variation dans le message obtenu en changeant de point de vue, d'éclairage. Elle se justifie quand on s'aperçoit que la traduction littérale ou même transposée aboutit à un énoncé grammaticalement correct, mais qui se heurte au génie de $L A^{1} »$.

En raison de leurs liens avec les structures du texte cible, le traducteur change les temps du verbe, le singulier et le pluriel, le positif et le négatif et le féminin et le masculin selon les caractéristiques grammaticales et la structure de la phrase de la langue d'arrivée.

- Expression du temps

Observons la traduction de ce vers du poème «Bénédiction » :

\begin{tabular}{|c|c|}
\hline \multicolumn{2}{|c|}{$\begin{array}{l}\text { Baudelaire : Lorsque, } \\
\text { Le Poète apparaît en ce monde ennuyé, }\end{array}$} \\
\hline سلام: عِنْدَمَا، & الطيار : عندما \\
\hline تَجَلَّلى الثََّّاِِرِ فِي هَذَا الْعَالَمِ & يظهر الشاعر في هذا العالم \\
\hline
\end{tabular}

1) VINAY, J. P. et DARBELNET, J., La stylistique comparée du français et de l'anglais, op.cit, p. 51

April 2016 


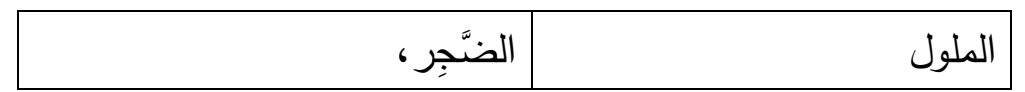

Pour le verbe «apparaît» conjugué au présent, Salam a recours à la modulation en le rendant en arabe par un verbe au passé (تَجَلَّى), alors qu'Al-Tayar choisit le verbe (يظهر) conjugué au présent. Les deux verbes (يظهر - نَجَاًَى) sont presque synonymes. Mais, ils pourraient nuire au sens. En effet, le traducteur est celui qui conserve l'intégrité de rapport entre les concepts et la langue. Pour exprimer de façon adéquate, il doit retrouver la réalité cachée derrière les mots, c'est-à-dire "une déverbalisation complète, une prise de conscience de ce dont il s'agissait ${ }^{l} \gg$. En tant que le verbe «apparaît», dans ce contexte, est figurément employé, la traduction n'est pas adéquate. Le sens concerne la naissance du poète. Nous devons le rendre par son sens propre (يولد - naître) qui garde la même idée que la langue source.

- Expression du négatif et de l' affirmatif

Prenons cet exemple du poème «Bénédiction » :

\begin{tabular}{|c|c|}
\hline \multicolumn{2}{|c|}{$\begin{array}{c}\text { Baudelaire : Elle avale ainsi l'écume de sa haine, } \\
\text { Et, ne comprenant pas les desseins } \\
\text { éternels,.. }\end{array}$} \\
\hline سلام : هكذا تبتلع زبد & الطيار : وهكذا تجرعت المرأة زبد \\
\hline كراهيتها، & حقدها \\
\hline وإذ لا تعي الأقدار الأبدية & وهي تجهل أن القدر المحتوم.. \\
\hline & \\
\hline
\end{tabular}

1 ) LEDERER, M. La traduction aujourd'hui, op.cit, p. 114 
La traduction poétique entre la littéralité et l'adaptation Dr.Magdi Adli Ahmed

Sallam donne une traduction presque littérale avec le même ordre des mots et suit le rythme de la phrase française. Il suit fidèlement le style de Baudelaire : il ne fait pas le changement de place des mots dans sa traduction. Tous les mots de la source sont précisément traduits. Mais le traducteur ne doit pas toujours avoir recours au mot à mot parce que cela conduirait d'ailleurs à une très mauvaise copie. Al-Tayar, dans sa version, a recours à la modulation en rendant une phrase négative «et ne comprenant pas» par une autre affirmative (وهي تجهل). Il transforme également le pluriel «les desseins éternels» au singulier : (القدر الدحتوم). Dans la traduction de ce fragment «les desseins éternels ", les deux traducteurs ne font pas d'excellent passage de la langue française dans la langue arabe. Nous voyons qu'ils perturbent le texte original.

- Expression du singulier et du pluriel «nombre »

Prenons cet exemple du poème « au lecteur » :

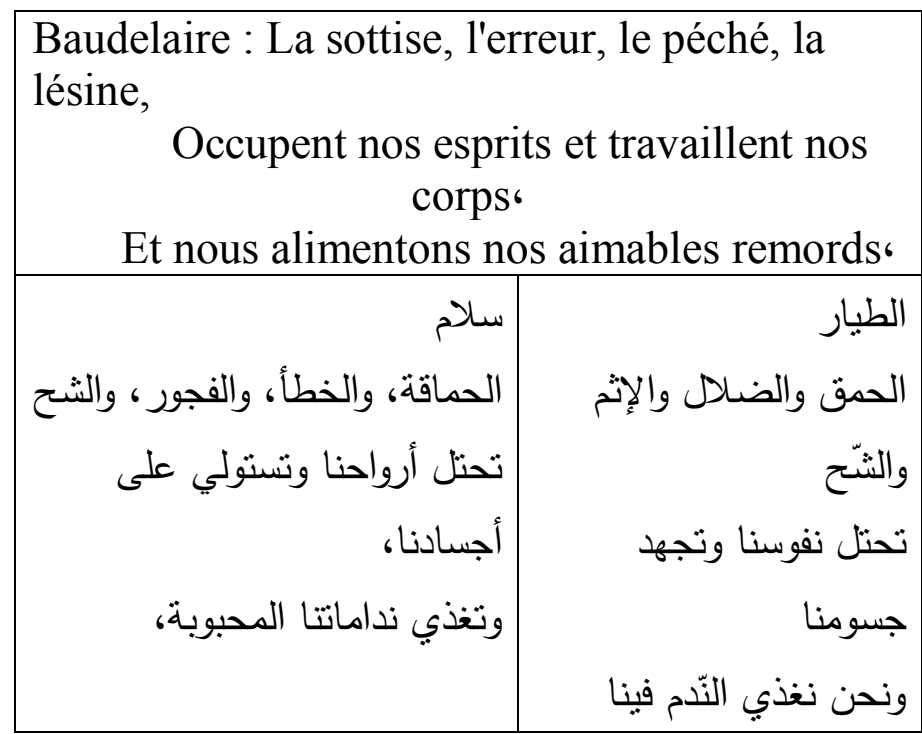

April 2016 
Ces vers sont analysés plutôt du point de vue de la modulation. Elle concerne la question du nombre. La grande dissimilitude entre le texte original et la traduction de Sallam est la transformation du pronom personnel pluriel par un pronom personnel singulier. Dans le vers baudelairien, le sujet s'exprime à la première personne du pluriel «nous alimentons », mais Sallam prend pour sujet la troisième personne du féminin

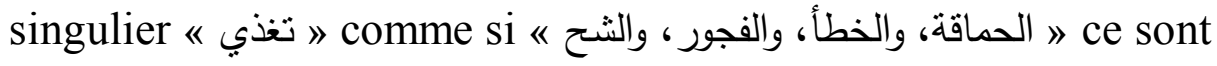
qui alimentent nos aimables remords. A notre avis, c'est une traduction inappropriée, et conduit au faux-sens. Car l'action du verbe «alimenter» nous appartient. C'est-à-dire c'est nous qui alimentons nos aimables remords. Al-Tayar ne modifie pas la structure de la phrase originale "ونحن نغذي " . Alors, le sens général du vers n'est pas modifié dans sa traduction par rapport au texte source.

Citons cet autre vers pris du poème «les Phares » :

\begin{tabular}{|c|c|}
\hline \multicolumn{2}{|c|}{$\begin{array}{c}\text { Baudelaire : Delacroix, lac de sang hanté des mauvais } \\
\text { anges, }\end{array}$} \\
\hline 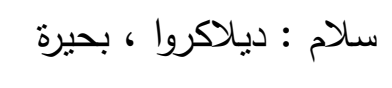 & De Lacroix) \\
\hline دماء تغشاها ملائكة شريرة & 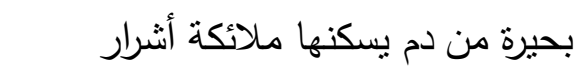 \\
\hline
\end{tabular}

Dans la langue française, l'adjectif qualificatif se trouve ordinairement après le nom "sang hanté », et avant le nom dans certains cas «des mauvais anges »; dans la langue arabe, dans la plupart des cas, l'adjectif qualificatif se trouve après le nom (ملائكة شريرة). Ayant recours à la modulation, Sallam nous donne une traduction presque littérale, mais cette traduction est absolument compréhensible dans la langue arabe, et par conséquent, c'est une traduction adéquate. Le nom singulier 
La traduction poétique entre la littéralité et l'adaptation Dr.Magdi Adli Ahmed

français «sang » est fidèlement traduit par le nom pluriel (دماء), et la tournure plurielle «des mauvais anges » est rendue par la tournure singulière (ملائكة شريرة).

- Expression du pluriel et du singulier «nombre»

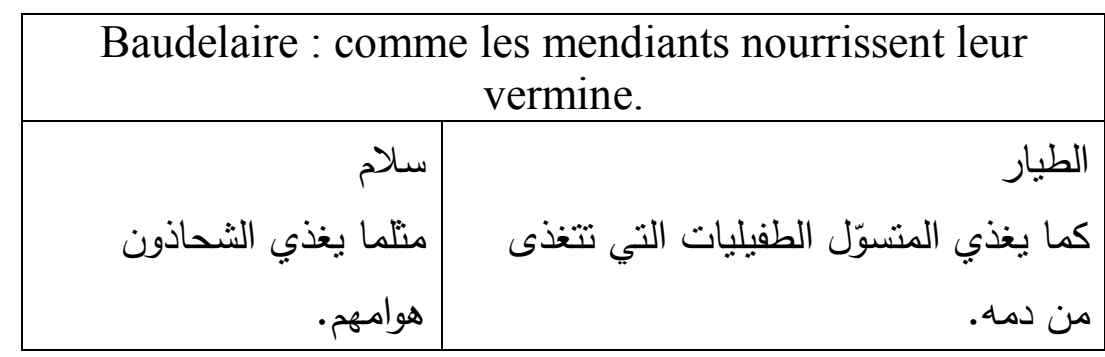

Le passage du pluriel «les mendiants » dans le texte arabe au singulier (المنسوّل) dans la traduction est de l'ordre de la modulation, c'est-à-dire une modification destinée à se conformer aux usages des collocations dans la langue d'arrivée.

\subsection{Procédés tout courts (ajout et omission)}

L'ajout et l'omission constituent des phénomènes linguistiques universels dont ses manifestations varient d'une langue à l'autre. Ces deux procédés accompagnent toujours toute opération de traduction quelque soit son genre. Les traducteurs peuvent ajouter ou effacer quelques mots surtout à la traduction de la poésie pour parvenir à l'esthétique et à la signification dans la langue cible. Cette approche pourrait être acceptable si les traducteurs conservent inévitablement les éléments originaux. Sinon il n'existera pas de traduction. «La traduction entraîne 


nécessairement certains ajouts et certaines omissions
d'information ${ }^{1} »$.

Nous voyons que le traducteur peut aller plus loin, mais sans pour autant «trahir» le texte de départ. Il nous semble qu'une certaine créativité est de mise et que des choix plus audacieux auraient pu être osés. Pour garder les messages et les idées de Baudelaire, le traducteur doit quelquefois accepter d'introduire et de renoncer à rendre certains éléments. Insistons alors sur le fait «de ne pas traduire des mots mais des phrases, de façon à rendre le sens sans rien perdre de la pensée et de l'émotion exprimées par l'auteur. Ceci peut se faire que par une tricherie perpétuelle qui amène le traducteur à s'éloigner beaucoup du texte ${ }^{2} »$.

Mais, nous devons avoir recours à ces deux procédés sans une superfluité ou une diminution et sans faire abus de son emploi afin de ne pas nuire au sens et déformer le message envoyé aux lecteurs. C'est-à-dire, le traducteur doit être fidèle au sens source. En effet, tout ajout et toute omission, dans le texte cible, sont, d'une part, dû aux différences linguistiques et culturelles de deux langues, d'autre part, pour lever l'ambiguité existant dans la langue de départ.

La traduction exige incontestablement la compréhension $\mathrm{du}$ message du texte original. Comprendre un texte exige la connaissance de la langue dans laquelle il est exprimé. Le traducteur qui s'intéresse à faire passer un texte d'une langue à une langue doit connaître ces deux langues. Grâce à la facilité d'exprimer, il est préférable de traduire dans la langue maternelle du traducteur.

1 ) GILE, Daniel, La traduction, la comprendre, l'apprendre, PUF., Paris 2005, p. 56

$\left.{ }^{2}\right)$ VINAY \& DARBELNET, stylistique comparée du francais et de l'anglais, op.cit, p.267 
La traduction poétique entre la littéralité et l'adaptation Dr.Magdi Adli Ahmed

\subsubsection{Ajout}

"Les additions sous forme de paraphrases, de gloses, de compensations et de renforcements se rencontrent fréquemment. Les traductologues ont maintes fois constaté que les traducteurs littéraires ont tendance à expliciter le texte, dans le but, semble$t$-il, d'amener le lecteur du texte d'arrivée à mieux en saisir le sens $^{1} \gg$.

Examinons, tout d'abord, ce procédé. Le traducteur peut ajouter des mots pour préciser le sens de sa traduction : nous trouvons fréquemment, dans la traduction arabe, l'ajout des conjonction, des prépositions, des propositions, des adjectifs, des noms et des pronoms etc.. Il a recours à rallonger ou ajouter des termes pour acquérir le sens désiré.

-Ajout de conjonction de coordination

Le fait d'ajouter de connecteurs est un fait plus contraignant. Voilà un exemple tiré du poème «Au lecteur » :

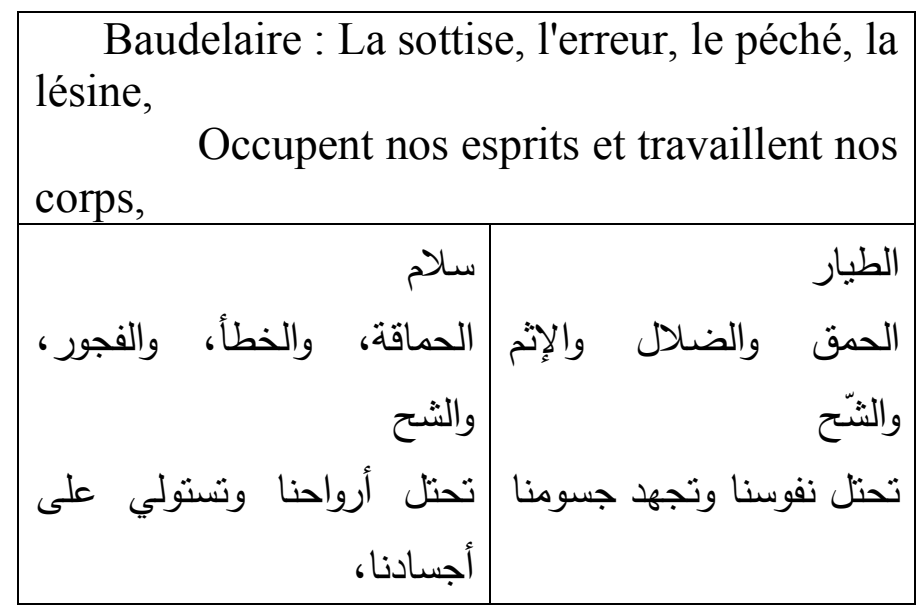

1 ) DUSSART, André, Faux sens, contresens, non-sens... un faux débat ? Meta : journal des traducteurs, vol. 50, $n^{\circ} 1,2005$, p. 116 
Remarquons que les traducteurs ont traduit les termes «La sottise, l'erreur, le péché, la lésine, " en ajoutant la conjonction de coordination " $g$ - et» ne figurant pas dans le texte source. Le connecteur " $\mathrm{g}-$ et $»$ marque la succession. Blachère souligne que "la conjonction wa, en phrase simple unit les termes de fonction identique $^{I} »$. Cet ajout est généralement causé par la particularité de la langue arabe. La conjonction " $g$ - et », obligatoire en arabe, est l'équivalent d'autant de virgules en français. La conjonction, appelé aussi connecteur permet de lier le contenu d'une phrase au contenu de celle précédente ou suivante. De plus, Sallam, dans sa version, conserve aussi le même ordre syntaxique et garde les mêmes virgules que l'original 《" الحماقة، والخطأ، والفجور، والثح expérimentés usent davantage les connecteurs au cours de la traduction.

-Ajout de préposition et de proposition relative

Prenons ce vers du poème "Au lecteur »:

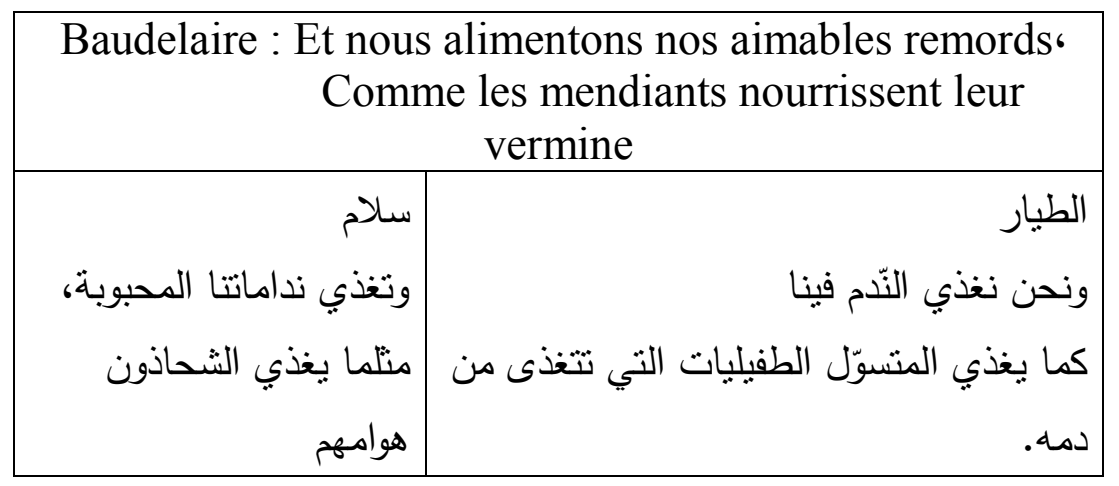

1 ) BLACHERE, R. Grammaire de l'arabe classique, Maisonneuve et Larousse, Paris, 1952, pp.473/474

April 2016

98

Vol. 44 
La traduction poétique entre la littéralité et l'adaptation Dr.Magdi Adli Ahmed

La traduction d'Al-Tayar a entraîné bon nombre de maladresse. Entre l'original et sa version arabe, il existe des écarts. La traduction contient de nombreuses indications concernant l'ajout et l'effacement de mots. Elle est inacceptable pour deux raisons: Premièrement, parce qu'il a remplacé l'adjectif possessif «nos » par la préposition (في), annexé par le pronom (ن) et omis l'adjectif « aimables » figurant dans le texte source. Deuxièmement, parce qu'il a inutilement ajouté la proposition relative : التي تتخذى من دمده pe figurant pas dans le texte original. Ce sont des ajouts non justifiés. Il a recours à la redondance et la phrase est vainement devenue plus langue. Il est intéressant de noter que cet ajout ne figure pas dans la traduction de Sallam qui est parfaitement acceptable et pertinente, même du point de vue de sa musicalité. Il a suivi la même structure que la phrase française.

-Ajout de nom

Nous retrouvons l'ajout d'un terme explicatif dans la traduction de l'exemple suivant du poème «Bénédiction » :

\begin{tabular}{|c|c|}
\hline \multicolumn{2}{|c|}{$\begin{array}{l}\text { Baudelaire : puisque tu m'as choisie entre toutes les } \\
\text { femmes }\end{array}$} \\
\hline 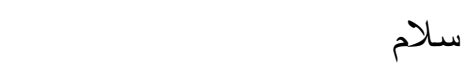 & الطيار \\
\hline وطالما أنك اخترنتي من بين كل & بما أنك با رب اخترتتي من بين \\
\hline النساء & النساء جميعا \\
\hline
\end{tabular}

Dans cet exemple, Al-Tayar ajoute l'unité lexicale (رب) précédé de la particule d'apostrophe (يا) dans la traduction tandis que, dans l'original, le pronom $(T u)$ remplace l'unité lexicale 
(رب). La nécessité d'introduire un terme explicatif nous semble un fait plus contraignant. La présence de la particule indique le vocatif qui reflète le cas de la mère épouvantée et pleine de blasphèmes et qui crispe ses poings vers Allah pour la prendre en pitié. Cet ajout ne figure pas dans la traduction de Sallam.

\section{-Ajout d'adjectif}

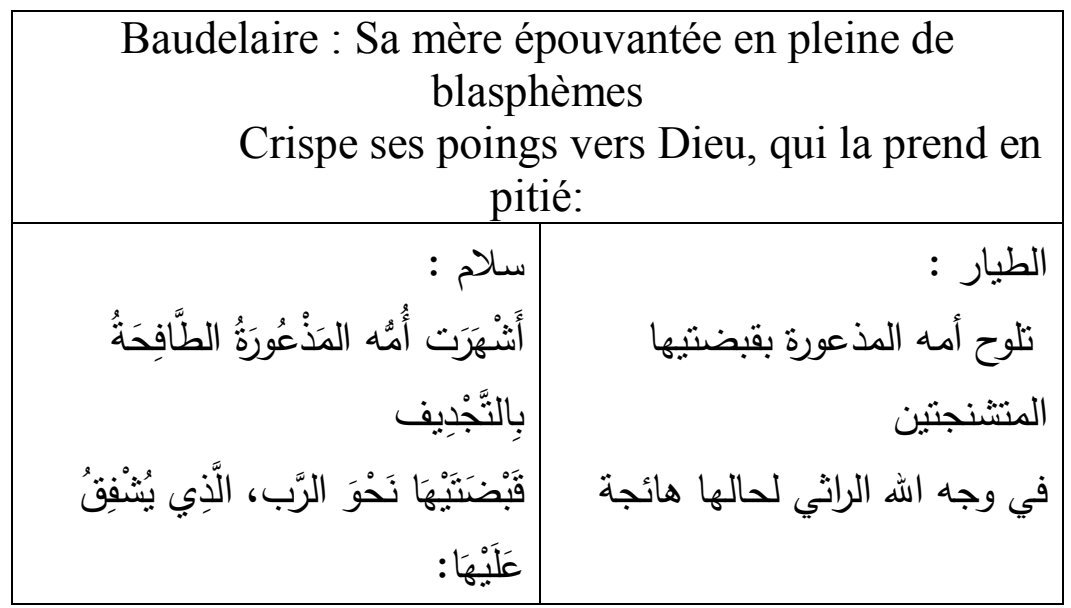

Cet exemple illustre la méthode de Sallam, qui semble traduire un mot après l'autre, sans recul par rapport à la phrase entière. Il veut préciser le sens de sa traduction, et ajoute un adjectif qualificatif qui ne se trouve pas dans la phrase de Baudelaire. Il traduit l'adjectif "épouvantée » par double adjectif.

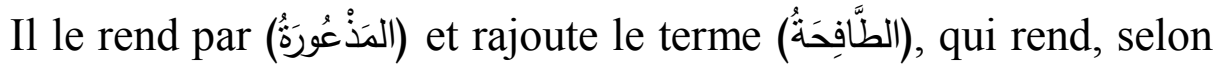
lui, la compréhension du lecteur possible, mais malaisée. Ce mode de traduction est une méthode habituelle. Al-Tayar, de sa part, choisit le terme "المذعورة" Mais, nous préférons la simplicité en se contentant de le traduire par « الخائفة 》. De plus, Al-Tayar introduit, de façon non justifiée, dans le texte d'arrivée 
l'adjectif superflus « هائجة ». En fait, il veut préciser le sens de sa traduction, et il ajoute un adjectif qualificatif inexistant dans la phrase de Baudelaire. Signalons que les ajouts sont fréquemment existés dans la traduction de la poésie baudelairienne pour des questions significatives, en raison de la différence des structures grammaticales de deux langues. Mais il faut éviter la superfluité afin de ne pas nuire au sens et déformer le message envoyé aux lecteurs.

Un autre exemple de l'ajout est fourni par cet autre passage :

\begin{tabular}{|c|c|}
\hline \multicolumn{2}{|c|}{ Baudelaire : les desseins éternels } \\
\hline سلام: الأقدار الأبدية & الطيار : القدر \\
\hline المرسومة & 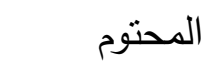 \\
\hline
\end{tabular}

Étant donné que le français est une langue moins concise syntaxiquement et lexicalement que l'arabe, Sallam a tendance à développer la traduction en arabe en raison de clarté. Au nom $d u$ souci de clarté, il n'est rare se trahir le texte ${ }^{l}$. Dans sa version, Sallam a renforcé le sens en rendant l'adjectif «éternels» par double adjectif (الأبدية المرسومة). Il ajoute l'adjectif (المرسومة) dans la traduction en arabe, n'étant pas sûr que l'adjectif (الأبدية) transmet complètement la signification voulue. D'un point de vue technique, nous considérons l'ajout «non justifié» comme une «faute de traduction».

\section{-Ajout de pronom}

Prenons cet exemple du poème «les Phares » :

1) MICHEL, Jacqueline, les enjeux de la traduction littéraires, op.cit, p. 27 April 2016 


\begin{tabular}{|c|c|}
\hline \multicolumn{2}{|c|}{$\begin{array}{l}\text { Baudelaire : Delacroix, lac de sang hanté des mauvais } \\
\text { anges, }\end{array}$} \\
\hline سلام : ديلاكروا ، بحيرة & الطيار : (De Lacroix-دي لاكروا) يا \\
\hline دماء تغشاها ملأككة شربرة & بحيرة من دم بسكنها ملائكة أنشرار \\
\hline
\end{tabular}

Etudiant les deux traductions, nous remarquons qu'AlTayar et Sallam ont recours au procédé de l'ajout très nécessaire dans la traduction du participe passé français "hanté» par les verbes "نغشاها- يسكنها " Tous les deux ont ajouté le pronom «ه annexé au verbe et qui appartient au mot 《lac بحيرة- 》. La traduction adéquate résulte d'une bonne appréciation de l'énoncé dans la langue source. Nous devons prendre en considération que toute intrusion de mots et de tournures peut conduire à une disharmonie qui déconcerte un lecteur cultivé, «quand bien même on la jugerait propice à l'effet d'immédiateté ${ }^{1} »$.

\section{-Ajout de parenthèses}

Les parenthèses servent à isoler un mot ou un groupe de mots à l'intérieur d'une phrase pour ajouter une explication, un commentaire, une précision sans lien syntaxique avec le reste de la phrase. En analysant notre corpus, nous remarquons fréquemment l'ajout de parenthèses dans la traduction arabe. Nous pouvons dire que, le plus souvent, Al-Tayar, dans sa version, a employé des parenthèses pour attirer l'attention des lecteurs sur une unité lexicale ou sur une locution placées entre parenthèses.

Citons ces exemples pris du poème «les Phares » :

1 ) ELLRODT, Robert «Comment traduire la poésie ? ", Palimpsestes [En ligne], Hors série | 2006, URL : http://palimpsestes.revues.org/247 
La traduction poétique entre la littéralité et l'adaptation Dr.Magdi Adli Ahmed

Baudelaire : Rubens, fleuve d'oubli, jardin de la paresse,

Al-Tayar : بانهراً للنسيان وبستاناً للكسل (Rubens- ريبنز).

Baudelaire : Léonard de Vinci, miroir profond et sombre,

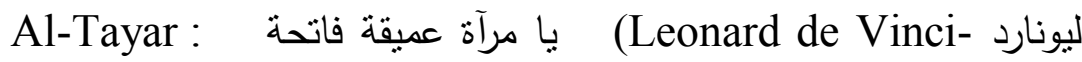

(دافنشي)

Baudelaire: Michel-Ange, lieu vague où l'on voit des hercules

Al-Tayar : أيها المكان الغامض الذي تختلط فيه العمالقة (Michel Ange - مايكل اونج)

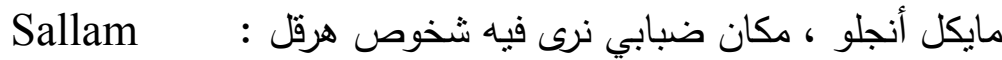

Dans ces exemples le traducteur attire l'attention sur les noms des artistes : (Rubens- ليونارد ), (Leonard de Vinci-) دافنشي), (Michel Ange - مايكل اونج) pour souligner leur importance.

Signalons enfin que plusieurs ajouts sont observables dans les différentes traductions pour certaines raisons. D'abord, les traducteurs ont précautionneusement introduit des éléments inexistants dans la version arabe afin de compenser l'impuissance et l'incapacité de la langue source. Deuxièmement, l'ajout est un procédé explicatif lors de la traduction. Il doit être harmonieusement intégré dans le texte arabe. Le traducteur essaie d'expliciter ce qui est implicite et opaque pour développer le message source. Il ambitionne en effet à rendre plus claires tout ce qui est brumeux dans la langue de départ.

\subsubsection{L'effacement}

En traduisant du français vers l'arabe, nous constatons que ce dernier laisse souvent implicite ce que le premier marque April 2016 
clairement : ce type d'opération se nomme "effacement ou omission ». L'omission est un phénomène linguistique général qui existe dans toutes les langues humaines. C'est un processus de retouche qui crée une agitation et une atmosphère poétique. Elle consiste à omettre un ou plusieurs termes dans une traduction donnée. Elle implique le processus inverse dit d'ajout, qui consiste à insérer une nouvelle unité dans un texte donné. : "L'omission consiste à ne pas rendre dans le texte d'arrivée un élément de sens du texte de départ sans raison valable ${ }^{l} »$. C'est un processus familier effectué "quotidiennement à de multiples occasions $^{2} \gg$.

Le procédé de l'effacement aide le traducteur à éviter le superflu, les redondances et les lourdeurs. Le traducteur doit prendre en considération que ce procédé ne conduit pas à dénaturer le sens et à l'ambiguïté. Il pourrait ajouter, au cours du processus de l'effacement, un indice indiquant le terme effacé. Le traducteur doit essayer de restituer tout le sens, mais rien que le sens. Les omissions permettent d'éviter des redondances et des lourdeurs ${ }^{3}$.

Il faut prendre en considération que "Si un élément d'une phrase peut être effacé, c'est qu'il joue le rôle d'un constituant facultatif ; inversement, si son effacement rend la phrase agrammaticale, la conclusion s'impose qu'il s'agit d'un élément nécessaire sans lequel la construction d'ensemble qu'est une phrase deviendrait boiteuse ${ }^{4} »$.

\footnotetext{
1) DELISLE et al. Terminologie de la traduction, John Benjamins coll. Amsterdam, 1999 , p. 47

$\left.{ }^{2}\right)$ RIEGEL, Martin. Les opérations linguistiques de base (suite) : L'effacement et l'addition. In: L'Information Grammaticale, N. 16,1983 . p. $10 . \quad$ URL : http://www.persee.fr/doc/igram 0222-9838 1983 num 16162317

$\left.{ }^{3}\right)$ DUSSART, André, Faux sens, contresens, non-sens... un faux débat ? op.cit, p. 115

$\left.{ }^{4}\right)$ RIEGEL, Martin. Les opérations linguistiques de base (suite), op.cit, p. 10 
Le traducteur peut supprimer un nom, un adjectif, un verbe, des groupes de mots faciles à rétablir, des conjonctions et des prépositions. Il convient également de faire part de quelques pertes qui surviennent immanquablement lors de la traduction de Sallam et Al-Tayar. Nous citons le cas du poème "Bénédiction» de nombreux passages ont été supprimés :

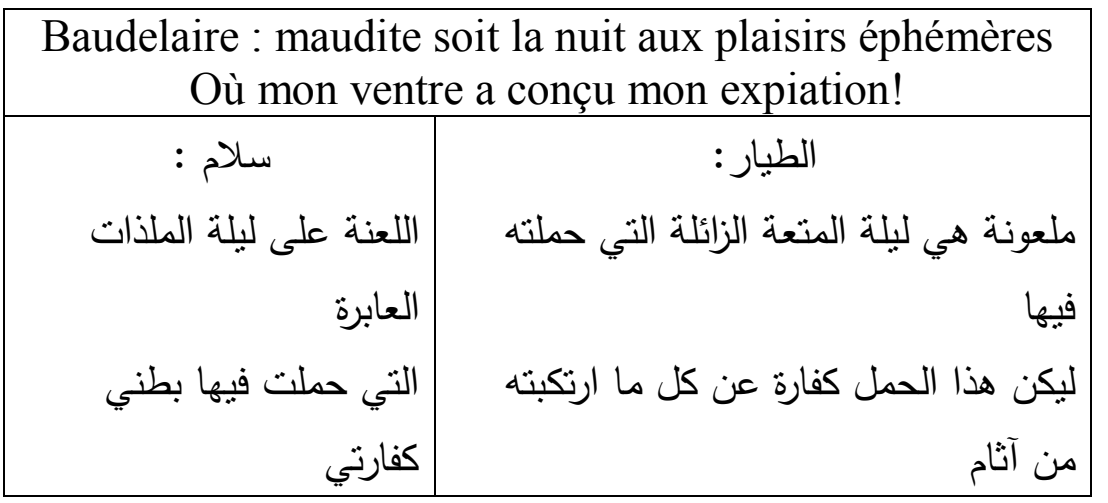

Etudiant les deux traductions nous observons maintes différences. Sallam a recours à la traduction littérale, et, avec concision, il a parfaitement donné le sens. Tandis que Al-Tayar, avec redondance, a recours à la traduction interprétative pour donner un sens clair et parfait. "Elle consiste à transférer des sens identiques d'une langue à l'autre dans l'équivalence des formes ${ }^{1} »$. Dans ce type de traduction, le traducteur prend conscience des sens d'un texte puis le réactualise en un nouveau texte dans une langue différente. Elle est également " caractérisée par un grand nombre d'omission et d'ajouts et par de nombreux réagencements de l'ordre des idées ${ }^{2} \gg$.

Nous remarquons que Al-Tayar, dans sa version, a magistralement rendu le message source en omettant le nom

1) LEDERER, M. La traduction aujourd'hui, op.cit, p. 216

2) DELISLE, J., La traduction raisonnée, Presse de l'Université d'Ottawa, Ottawa, 1993, p. 48 
"mon expiation » qui se traduit en arabe par " كفارتي ». Mais ce terme dans ce contexte est employé dans son sens figuré. Il désigne en effet "l'enfant dérisoire ». La première tâche du traducteur est de détacher de la notion fort imprécise du mot. Etant qu'un traducteur adroit, Al-Tayar a effacé ce nom en le remplaçant par l'emploi du pronom suffixe « $₫$ » annexé au verbe " هملت " هاء " Le pronomdique l'indice ou la preuve qui contribue à la connaissance de l'élément effacé et la compréhension du sens. Le syntagme nominal "mon expiation » est remplacé dans la traduction d'Al-Tayar par le pronom «ه» qui renvoie à un complément de la phrase.

Nous pouvons citer cet autre exemple :

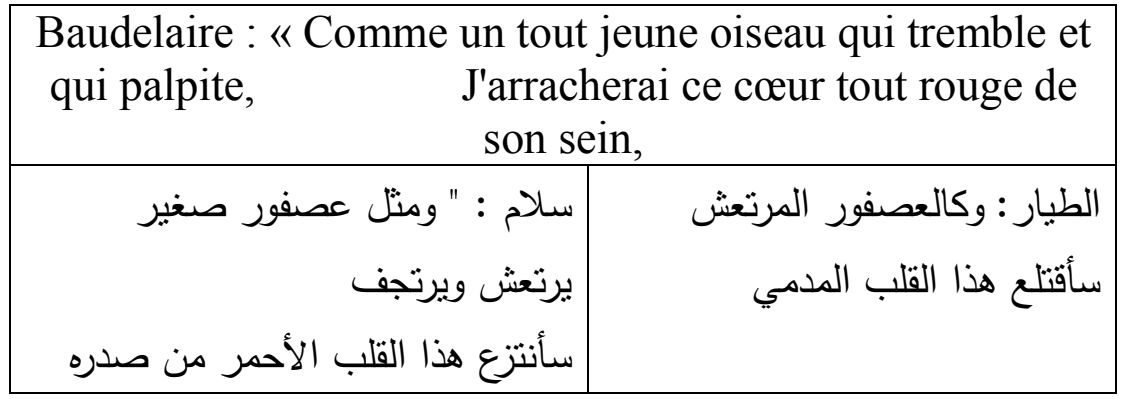

Al-Tayar recrée le vers en arabe et omet certains termes, ce qui a pour effet d'approcher de la traduction du texte source. Il a également recours à la condensation en mélangeant des éléments de plusieurs vers de Baudelaire dans un seul vers arabe. La traduction est en effet appropriée car nous renvoyant au sens des vers. L'omission, comme une forme de transformation faite par le traducteur, comprend l'effacement des mots qui ne sont pas indispensables pour la compréhension du message original. Pour des raisons stylistiques, Al-Tayar a tout d'abord omis l'adjectif 《jeune - صغير》 et le verbe "palpite - يرتجف. Etant donné que April 2016 
les deux verbes 《palpite - بيرتجف et 《tremble - يرنتش sont presque synonymes, le traducteur a préféré la simplicité en rendant un seul verbe «tremble - يرتشش). La répétition inutile pourrait déformer la souplesse de la langue cible. Et comme c'est " un oiseau qui tremble », il est alors " jeune », ce qui pousse le traducteur à ne pas rendre l'adjectif "jeune» en arabe. Egalement, la tournure 《de son sein - من صدره" ne figure pas dans la traduction d'Al-Tayar en raison d'omettre les termes superflus. Les deux traducteurs ont effacé le pronom relatif " qui » répété deux fois dans le texte source, car sa transmission pourrait porter atteinte à la souplesse de la langue arabe et conduire à la lourdeur et à l'inexactitude de la traduction. Cependant, ce procédé ne porte pas tort à la compréhension du message du texte cible.

Quelquefois, le traducteur a recours à l'omission d'un ou plusieurs vers au nom du souci de clarté, ou sans raison connue, comme le fait Al-Tayar qui a supprimé deux vers lorsqu'il a traduit le poème de «Bénédiction ».

Observons à présent la traduction de ce vers :

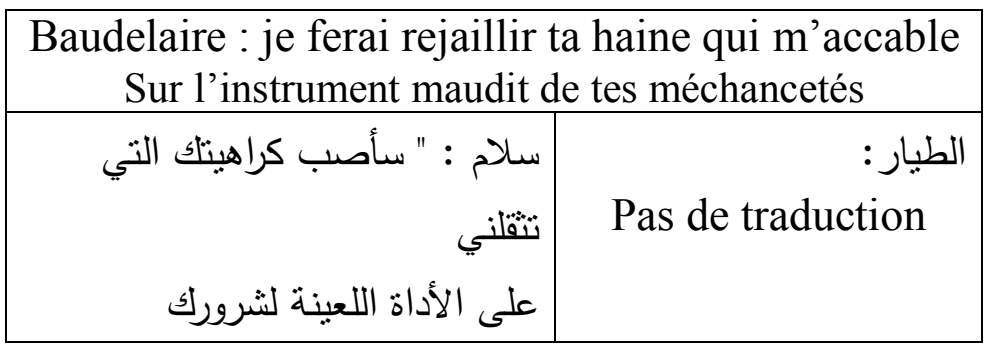

Sans raison valable, Al-Tayar omet de traduire plusieurs vers. En effet, c'est une trahison à la traduction. Par contre, Sallam nous donne une traduction tout à fait adéquate. Il suit très 
bien le rythme de la phrase française. Il traduit précisément et fidèlement tous les lexèmes. Dans le texte français les verbes se trouvent au futur "ferai rejaillir» et au présent «qui $m$ 'accable ", dans la traduction les verbes se trouvent aussi au futur (سأصب) et au présent (التي تثقلني).

Citons également cet exemple du poème «Bénédiction » :

\begin{tabular}{|c|c|}
\hline udelaire : et je tordrai si & en cet arbre misérable \\
\hline م : سأقطع تماما هذه الثجرة & هذه \\
\hline البائسة & \\
\hline
\end{tabular}

Les adverbes 《si bien - تماما 》qui s'intercalent entre le verbe et le complément, et l'adjectifs épithète 《 misérable - بائسة) qui postpose le nom «arbre » sont effaçables. Le procédé de l'allégement ou l'économie lexicale consiste à retirer un ou plusieurs termes inutiles. Les deux traducteurs essaient de rendre la poésie de Baudelaire en gardant les caractéristiques esthétiques de la traduction poétique. Nous remarquons que Al-Tayar a effacé l'adjectif (misérable - بائسة) et l'adverbe (si bien - تماما), lesquels apparaissent dans la version de Sallam, dotée d'un vocabulaire riche de la langue cible, et préfère la traduction littérale pour bien conserver la structure du texte en question.

Prenons ces autres exemples du poème "Bénédiction » :

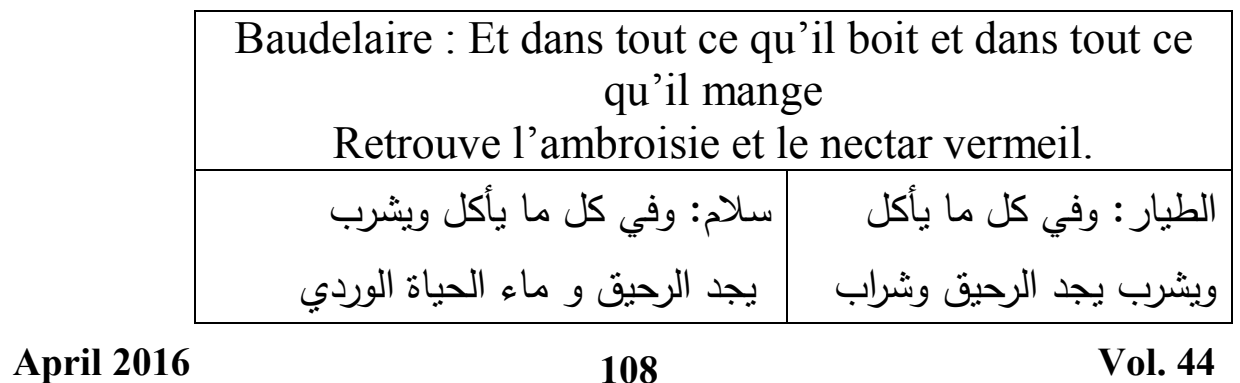




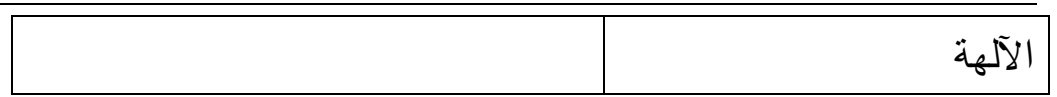

Conserver le message source, c'est entraîner parfois certaines omissions. Le traducteur ne doit pas s'éloigner du texte source. En l'occurrence, nous remarquons que l'adjectif "vermeil - وردي ne figure pas dans la traduction d'Al-Tayar. L'effacement est incontestablement accepté parce qu'il ne déforme pas l'intentionnalité du Poète. Egalement, son inexistence ne dénature pas le sens.

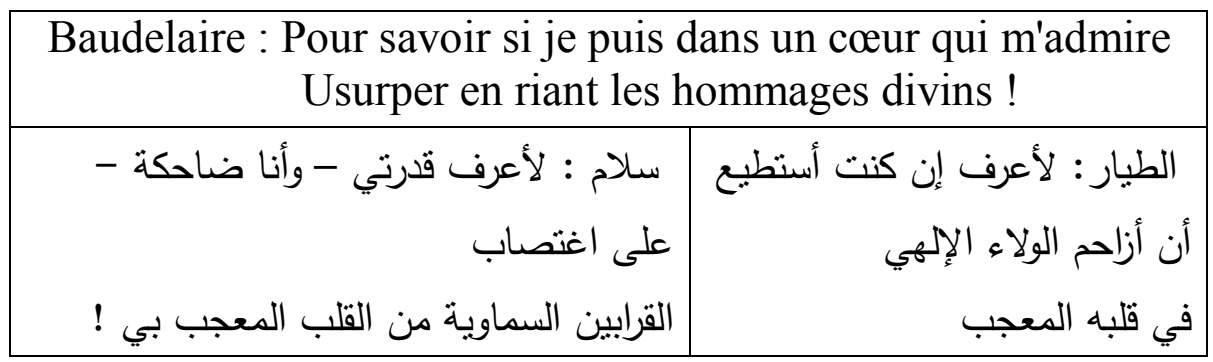

Il est facile de remarquer l'inexistence du participe présent " en riant » dans la version d'Al-Tayar, lequel est figuré dans la traduction de Sallam qui préfère le littéralisme (ضاحكة).

Il est vrai que la suppression des éléments sources peut se révéler une façon adéquate de traduire, à condition que la précision apportée dans la traduction n'ait pas d'impact sur la signification du message source. L'omission est une technique de traduction qui consiste à éliminer des éléments d'information du texte originale dans le texte d'arrivée. Le traducteur est souvent obligé à condenser l'information contenue dans certains passages d'une oeuvre. Pour ce faire, il pourrait supprimer certains éléments non indispensables et dont l'effacement améliore la qualité stylistique de l'oeuvre traduite. Ces suppressions 
produisent en arabe une impression de rapidité et créent des effets parfois saisissants.

\subsection{La traduction par permutation}

La permutation consiste à un changement de l'ordre des mots, sans impact sur le sens de la phrase. Il n'est pas seulement le résultat d'une option du traducteur, mais aussi il soumet à des différences de construction de chaque langue impliquée dans la traduction.

En arabe comme en français, il existe des éléments qui ne peuvent pas commencer la phrase.

Prenons donc ces exemples du poème «Bénédiction » :

\begin{tabular}{|c|c|}
\hline \multicolumn{2}{|c|}{$\begin{array}{l}\text { Lorsque, par un décret des puissances suprêmes, } \\
\text { Le Poète apparaît en ce monde ennuyé, }\end{array}$} \\
\hline سلام : عِدْدَمَا نَجَلَّى الثنَّاَعرِر & بظهر الثناعر \\
\hline 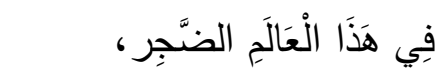 & 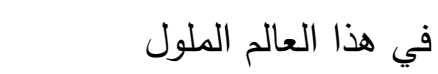 \\
\hline بقِقَرارِ مِنَ الْقُوَى الْعُعَلَيَا، & بقرار من القوى العلوية \\
\hline
\end{tabular}

Un fait stylistique apparait clairement dans la traduction de ce vers en arabe. Il existe des correspondants parfaits entre les deux traducteurs. Nous devons tenir compte les inversions ou les ordres des mots différents car il est tellement fréquent qu'il faille changer l'ordre des mots quand nous traduisons du français en arabe. Chacun commence magistralement sa traduction par le deuxième tercet. Il existe une inversion entre les éléments de la phrase en raison de l'expressivité et la particularité de la langue arabe. 
En arabe, nous ne pouvons pas suivre toutes les traces de la langue française. C'est-à-dire nous ne pouvons pas commencer la traduction par «ندما، بقرار من القوي". Les deux traducteurs ont respectueusement recours à la phrase verbale pour rendre le message de la langue source. Ils ont commencé leur traduction par Verbe, sujet, complément, phrase intercalée. Tandis que la langue du départ commence par Phrase intercalée, sujet, verbe, complément. Les traducteurs ont respecté le génie et la particularité de la langue arabe ayant recours à l'inversion des mots. En effet, l'ordre des mots en arabe diffère de celui en français du fait : " qu'il existe un ordre à respecter : verbe, sujet complément direct, complément circonstanciel ${ }^{l} »$. L'ordre des mots habituel du français est : sujet, verbe complément ou attribut. Mais, il faut insister sur le fait que « cette fixité n'est que relative et ne peut pas se maintenir à cause des inversions syntaxiques ou expressives qui abondent en français ${ }^{2}$ ". De là, l'ordre des mots peut apporter des résonances affectives à la phrase en la colorant et en lui donnant du rythme. Il pose en effet des problèmes syntaxique ou stylistique. Syntaxique parce que certaines inversions se produisent dans le cadre même de la grammaire, comme le cas de l'interrogation directe. Stylistique, parce que l'arabe étant essentiellement musicale, nous y trouvent fréquemment des inversions d'ordre rythmique : certains mots ou groupes de mots en antécédent d'autres pour exprimer avec précision le message de la langue source ${ }^{3}$.

Il est impossible en français de commencer la phrase par le prédicat verbal, tandis qu'en arabe c'est l'ordre le plus ordinaire. La position initiale des termes dans le texte source ne correspond

1 ) MONTEIL, Vincent, l'arabe moderne, Klincksieck, Paris, 1960, p.227

$\left.{ }^{2}\right)$ ALI, Magdi, les problèmes posés par la traduction en arabe du roman de Michel Tournier Vendredi ou la vie sauvage, thèse de Doctorat, Université de Provence, Marseille, 2006, p. 220

3) Ibid, p. 224

April 2016 
pas nécessairement à cette position dans la langue cible. Nous pouvons citer beaucoup d'autres exemples pris du poème «Bénédiction 》 :

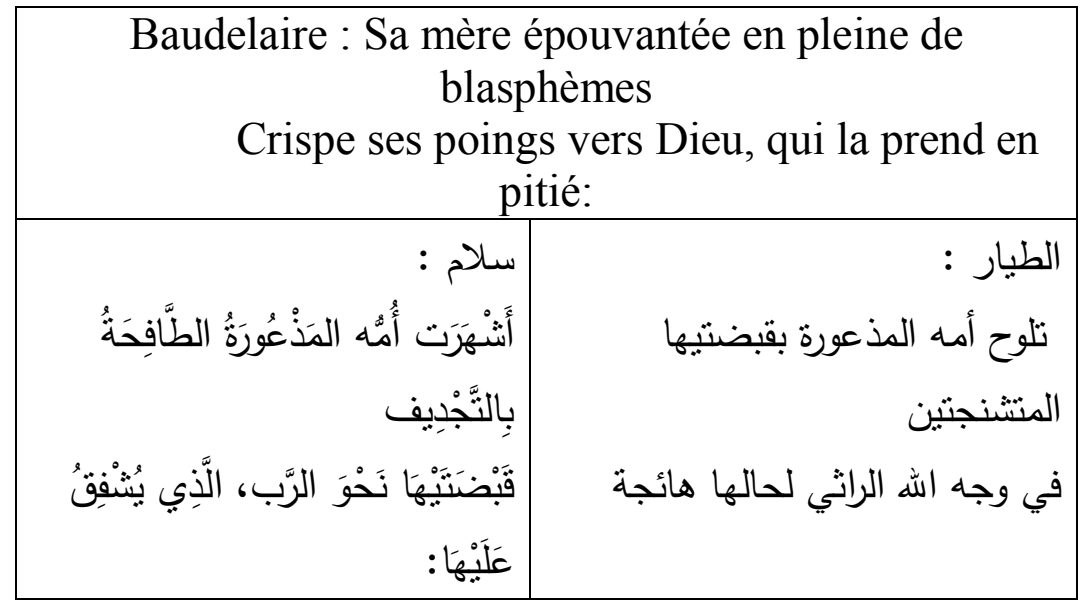

Les deux traducteurs ont recours à la phrase verbale pour transférer le message source. Leur traduction commence par : verbe, groupe sujet, complément, tandis que la langue source garde l'ordre : group sujet, verbe, complément. Ils font alors des inversions entre les éléments de la phrase en raison de l'expressivité et de l'harmonie de la langue cible.

Ces traductions ne donnent qu'une vague idée d'un des sens possibles de l'original. Elles n'ont plus aucun sens, elles deviennent absurdes, insignifiantes et insensées. Elles sont chétives. Les traducteurs ont pris la voie de la traduction littérale pour saisir le sens. Mais ils n'arrivent pas à comprendre l'idée originale. En fait, la première démarche de traduction est de détacher de la notion fort imprécisée du mot. Un mot ne prend souvent son sens qu'associe à un autre ou plusieurs autres. 
Lبض - شنج (قب ). Chacun de deux traducteurs a choisi un terme propre afin de bien suivre le sens du texte en français. Salam a recours à la modulation en rendant le présent «crispe»par le passé (أَنَّْهَرَتُ ), alors que Al-Tayar garde le même temps que français en le traduisant par (تلوح). Le verbe «crispe», dans ce contexte, est employé dans un sens figuré avec la signification de (مدت). Cependant, Salam a également respecté le temps du verbe du deuxième vers en remplaçant la tournure «la prend en pitié» par un seul verbe (يشفق). De sa part, Al-Tayar rend cette tournure par un nom (الراثي). Nous voyons que ces vers signifient: La mère effrayée et peur lève ses bras vers le ciel. Par conséquent, nous préférons pour autant une autre traduction :

$$
\text { (مدت الأم الخائفة أكف الضراعة إلى اله الرحيم بها.) }
$$

Citons également ce vers pris du poème « Bénédiction » :

\begin{tabular}{|c|c|}
\hline $\begin{array}{l}\text { 3audelaire : Tous ceux qu'il } \\
\text { crai }\end{array}$ & 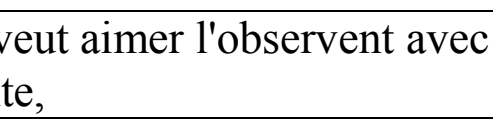 \\
\hline لم & الطيار \\
\hline فيراقبونه من كان يهفو إلى حبهر & وحبتهرج بخوف كل الذين يرغب في \\
\hline
\end{tabular}

Analysant la traduction en arabe, nous remarquons que la version d'Al-Tayar prend un chemin plus différent que le texte original. La différence touche principalement l'ordre des mots. Il commence sa traduction par un verbe conjugué à l'inaccompli « 
" et par un pronom annexé au verbe 《ه», tandis que l'original commence par la tournure "tous ceux qu'il veut ... ». Jamais le français commence par un verbe conjugué que dans le cas de l'inversion du sujet. Sa transmission et son écart du texte original ne modifient pas le sens du texte et ne déforme pas l'intentionnalité du Poète. Par contre, Sallam suit les traces de Baudelaire ayant recours à la traduction littérale. Il transmet le message presque de la même façon aussi que le texte source.

Prenons également cet exemple du même poème :

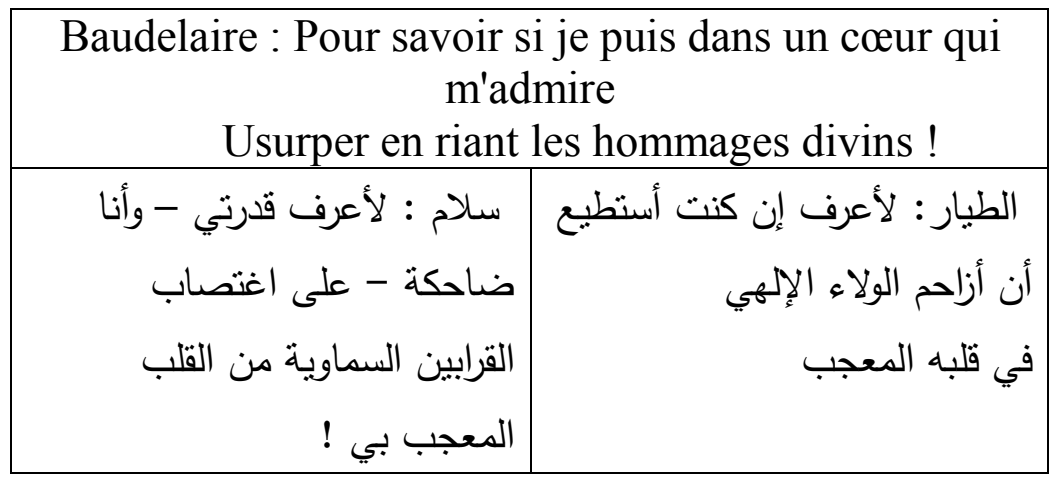

Les deux traducteurs ont sciemment bouleversé l'ordre des mots du poème source dans le bute de respecter les particularités de l'arabe. La position du syntagme nominal «dans un cour qui m'admire - هن القلب المجب بي! - في قلبه المعجب", dans le texte source, ne correspond pas nécessairement à cette position dans la langue cible. En français, ce syntagme est posé au milieu de la phrase, tandis que les traducteurs préfèrent de le mettre à la fin de la phrase arabe. Subséquemment, la position finale du syntagme nominal «les hommages divins - القرابين السماوية - الولاء الإلهي a a également pris sa place au milieu de la phrase traduite, qui rend la compréhension du lecteur possible et accessible. La tonalité et la signification du message source ne sont pas modifiées dans 
leur appropriation. Les deux traducteurs ont essayé d'adapter le message à leur propre style.

Prenons cet exemple tiré du poème « Bénédiction » :

\begin{tabular}{|c|}
\hline Baudelaire : Sauront jusqu'à son cœur se frayer un \\
chemin. \\
\hline : ستشق طريقها حتى قلبه : الطيار : تسنطيع أن تمهذ إلبه \\
\hline
\end{tabular}

Une traduction littérale de cet énoncé s'avère impossible. Les traducteurs ne pourront pas prendre la voie de la traduction littérale pour saisir le sens La traduction mot à mot est quelquefois considérée comme une solution inadéquate que le traducteur doit éviter. Les traducteurs ont recours à la traduction interprétative avec quelques ajouts et omissions, ainsi avec l'inversion des mots pour donner le sens parfait.

Ils font une inversion des mots lorsqu'ils ont traduit

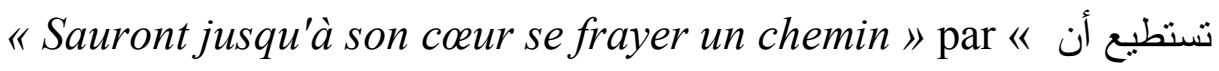
" ستشق طريقها حتى قلبه - تمهد الطريق إليه possible, l'expressivité et l'harmonie de la phrase arabe. Remarquons que Sallam a posé l'adverbe et le complément "jusqu'à son cour » à la fin de sa traduction حتى قلبها ". Il a également effacé le verbe "sauront». De son côté, Al-Tayar a recours à certains procédés de traduction. Ayant recours à la modulation, il a rendu le verbe conjugué au futur «sauront » et l'infinitif «se frayer » par des verbes à l'inaccompli نشتطيع انمهد. Il a également effacé le syntagme nominal «son cœur » et ajouté le pronom 《ه» annexé à la préposition 《إلى qui 
appartient au syntagme effacé et qui vient à la fin de la phrase. Les deux traductions sont acceptées malgré les remarques.

\subsection{L'intraduisible}

À cause de l'écart lexical existé entre les langues, il existe en effet beaucoup de termes n'ayant pas d'équivalents dans l'autre langue. Pour les mots non transcodables dites intraduisibles, «de nombreux penseurs se sont exprimés à propos de l'intraduisibilité ; évoquant la non-existence pour certains vocables de correspondance entre les langues, ils ont forgé l'expression "mots intraduisible". " Nous devrions classer en mots intraduisibles "tous les mots qui ne peuvent pas être traduits une fois pour toutes par le même mot, en somme, tous les mots autres que les termes mono référentiels ${ }^{2} »$.

Traduire tous les termes d'une langue à l'autre est impossible, car, entre les langues, il existe des mots n'ayant pas d'équivalents. Il s'agit plutôt d'une «lacune», c'est-à-dire l'absence d'un élément, d'une expression similaire. En somme, il n'existe pas d'isomorphisme entre les langues. Les expressions idiomatiques et les noms propres sont en effet intraduisibles en arabe. Il suffit de confronter deux traductions d'un même texte pour remarquer qu'elles peuvent diverger par rapport au texte original.

De sa part, Mounin insiste sur le fait que l'intraduisibilité " peut se mesurer soit en relevant, dans un ouvrage traduit, tous les mots non traduits en langue cible [..] ; soit en comparant deux traductions d'une même page, afin de confronter les accords et les désaccords des praticiens 》. Il ajoute également que le mot étranger est cité peut être «a) flanqué d'une

1 ) LEDREER, Marianne, La traduction aujourd'hui, op.cit, p. 74

2 ) Ibid., p. 76

April 2016

116

Vol. 44 
La traduction poétique entre la littéralité et l'adaptation Dr.Magdi Adli Ahmed

traduction, b) accompagné d'une glose (explication entre parenthèses ou virgules, ou avec "c'est-à-dire »), c) laissé seul ${ }^{1} \gg$.

La poésie de Baudelaire est parsemée des mots intraduisibles. Ses poèmes sont remplis de noms propres ayant un rapport avec le contenu. Il est donc impossible de les négliger. Il existe des noms propres, des noms communs et des adjectifs.

Les noms propres occupent, dans la poésie baudelairienne, une place importante et leur transmission oblige des stratégies spécifiques pour les rendre ou les arabiser. Nous devons voir une manière appropriée de la traduction. En principe, il faut désigner la manière la plus simple et la plus efficace pour transmettre le nom propre français même si elle semble inhabituelle.

En règle générale, et sauf exception, les noms propres ne se traduisent pas. S'ils sont parfois dépourvus de sens, ils peuvent se déplacer tels quels au cours de sa traduction d'une langue à l'autre. Il faut alors tenir compte des sons et non pas des lettres. Mais, ils peuvent être traduisibles pour certaines exceptions. Les noms de personnes restent en général tels quels, mais les noms de lieu ayant un sens particulier se rend par son équivalent. De là, signalons que "Lorsque le nom propre a un sens, implique une connotation, ou réfère à une entité déterminée dont la compréhension est indispensable à l'intelligibilité du texte, la traduction s'effectue en notes infrapaginales. Sinon, il appartient au traducteur de juger de la nécessité de telles notes ${ }^{2}$ 》.

1 ) MUONIN, G., les problèmes théoriques de la traduction, Gallimard, Paris, 1963, p. 191

2 ) SOBHY, Camélia, La traduction du nom propre, URL :

http://www.atida.org/french/index.php?option=com content\&view=article\&id=4:latraduction-d..

April 2016 
Prenons cet exemple tiré du poème « Bénédiction »

\begin{tabular}{|c|c|}
\hline & lyre, \\
\hline سلام : لكو المهرات الضائعة لبالمبرا & \\
\hline
\end{tabular}

Il est indispensable en transférant les intraduisibles en arabe de conserver la prononciation française. Le nom propre « " en arabe est emprunté phonétiquement à un mot français "Palmyre ». Sallam, dans sa traduction, respecte cet emprunt qui est, de plus, devenu couramment utilisé. Al-Tayar, par contre, le rend par son équivalent en arabe : "تدمر 》.

En raison de clarté, Sallam, de sa part, ajoute une note de bas de page dans laquelle il explique le sens du terme «بالميرا" disant que Palmyre (ville des palmiers) est une ancienne ville syrienne qui porte le nom "تدمر». C'était une ville forte et riche de laquelle la reine «Zénobie » a fait un royaume culturel brillant très connu.

Bien entendu, la traduction est souvent accompagnée d'une note du traducteur que le traducteur peut introduire dans le texte cible pour fournir au liseur toutes les informations nécessaires et utiles pour bien comprendre un passage difficile à rendre ordinairement dans la langue d'arrivée sans s'écarter du sens source.

Avec maintes différences, les deux traducteurs ont recours à l'intraduisible formé à partir d'adaptations phonologiques, tout en gardant la prononciation d'origine. Dans sa version, Sallam 
ajoute une note de bas de page explicative pour faire figurer la traduction d'une unité sémantique suffisante extraite de la poésie baudelairienne permettant de comprendre le simple syntagme originellement cité. Dans ses notes, il insère des informations significatives concernant les personnages cités dans certains de ses poèmes mis en question. Al-Tayar a recours à l'arabisation (translittération en arabe) tout en conservant également le français pour traduire les noms propres, sans avoir recours à une note signifiante de bas de page. Citons ces exemples pris du poème «les Phares » :

Baudelaire : Rubens, fleuve d'oubli, jardin de la paresse,

$$
\begin{aligned}
& \text { Al-Tayar : يانهاً للنسيان وبستاناً للكسل (Rubens- ريبنز). } \\
& \text { Sallam : روبنز , نهر نسيان, حديقة للكسل }
\end{aligned}
$$

En réalité, il n'existe de différence qu'au choix des termes en raison de l'aspect synonymique de la langue arabe بستاناً "حديقة, tout en aboutissant à un consensus car les deux traductions gardent le même sens et la même force d'expression $\mathrm{du}$ poème original. Il faut indiquer toutefois qu'en principe, les noms propres ne sont pas traduits. Rubens, par exemple, se rend par «وبنز". Il s'agit ici d'une façon d'emprunt en respectant le plus possible les sonorités du mot, en dépit de l'éloignement phonétique existant entre la représentation graphique de deux langues et leur différente prononciation. Cet emprunt s'effectue alors à l'aide de la translittération en arabe. Ces noms doivent s'écrire en arabe conformément à la prononciation correcte.

Dû à l'inexistence cognitive, de la part des lecteurs arabes, des personnages mentionnés dans le poème «les Phares», Sallam 
روبنز فنان " : ajoute ces mots explicatifs en note de bas de page 1640 - 1577 19ن.

Les noms propres sont capables de subir des changements lors de la traduction d'un texte source à un texte cible. Parfois, il faut avoir recours à la transcription des noms avec rectification de la prononciation, ex : "Léonard de Vinci » en français se traduit par ليونارد دي فينشي en arabe. Ils pourraient également rester maintenus dans leur forme graphique originale.

Baudelaire : Léonard de Vinci, miroir profond et sombre,

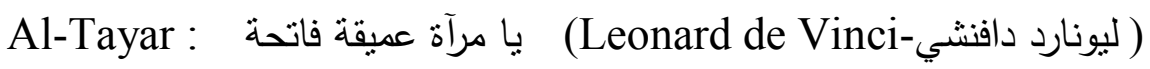

Sallam : ليونارد دي فنشي, مرأة عميقة معتمة

En note de bas de page, Sallam a également écrit un mot explicatif : «1519 - ليونارد دي فينشي : فنان ايطالي 1452 إ.

Citons également ces exemples qui suivent les mêmes démarches que dans les exemples précédents tout en démontrant que Sallam a toujours recours à la translittération en arabe pour rendre les noms propres et à l'ajout d'une note explicative du traducteur. Ils nous montrent également qu'Al-Tayar garde toujours les deux langues en rendant les noms propres.

Baudelaire : Rembrandt, triste hôpital tout rempli de murmures,

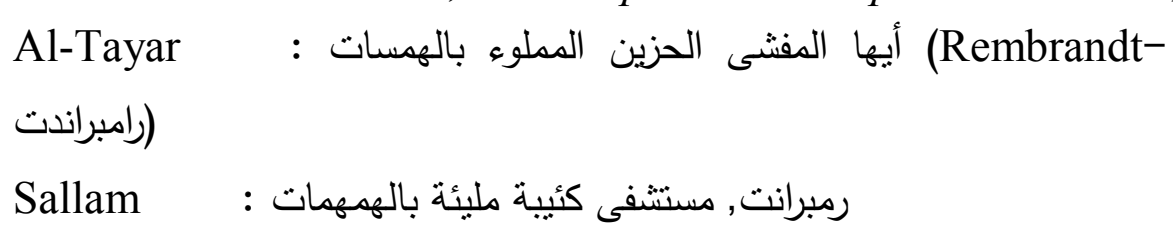

Dans la version de Sallam le nom propre est généralement adapté à l'usage de la langue cible. Al-Tayar a recours à la April 2016 
La traduction poétique entre la littéralité et l'adaptation Dr.Magdi Adli Ahmed

translittération du terme en arabe 《رامبراندت》", et à maintenir sa forme graphique originale «Rembrandt». En note de bas de

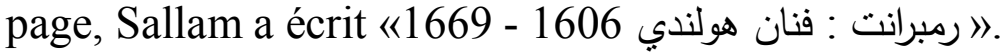

Baudelaire : Michel-Ange, lieu vague où l'on voit des hercules

Al-Tayar : أيها المكان الغامض الذي تختلط فيه العمالقة (Michel Ange

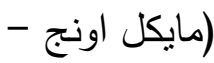

Sallam : مايكل أنجلو ، مكان ضبابي نرى فيه شخوص هرقل

مايكل انجلو : رسام " : En note de bas de page, Sallam démontre que 1564 - 1475 1ونحات ايطالي

Baudelaire : Puget, mélancolique empereur des forçats ;

Al-Tayar : : أيها الإمبراطور الحزين للمحكومين بالأثغال الثاقة :Puget(بيجي (ب)

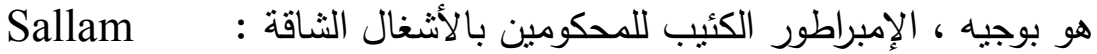

En note de bas de page, Sallam a écrit « - بوجيه : نحات فرنسي 1620 1694».

Baudelaire: Watteau, ce carnaval où bien des cours illustres, Comme des papillons, errent en flamboyant,
Al-Tayar
( ماتو-Watteau) أيها الكرنفال الذي
تهيم فيه القلوب الكبيرة مضيئة كالفراش
Sallam
وانو, هذا المهرجان الذي تهيم فيه منوهجة :
قلوب مبرقتشة, منل الفراثنات 
وانو : رسام فرنسي « En note de bas de page, Sallam a écrit $1684-1721 »$.

Baudelaire : Goya, cauchemar plein de choses inconnues,

$$
\begin{aligned}
& \text { Al-Tayar : : غويا-Goya) : أيها الكابوس الملوء بالأسرار الدهولة }
\end{aligned}
$$

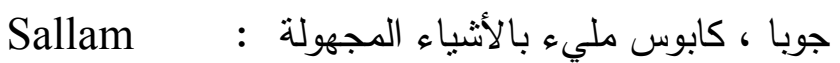

جوبا : رسام اسباني 1746 - « En note de bas de page, il a écrit $1828 »$.

Baudelaire: Delacroix, lac de sang hanté des mauvais anges,

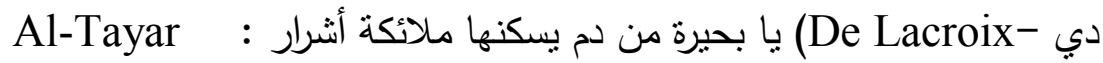
(لاكروا

Sallam : يلاكروا ، بحيرة دماء تغشاها ملائكة شريرة

En note de bas de page, il a écrit « ديلاكروا: رسام فرنسي 1798

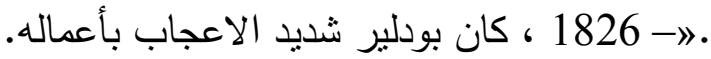

Baudelaire : Passent, comme un soupir étouffé de Weber ;

Ces noms propres sont des artistes du 15ème au 19ème siècle évoqués par Baudelaire et considérés comme "les phares » qui éclairent la route des Hommes. Dû à l'inexistence cognitive de ces phares, de la part des lecteurs arabes, Sallam devrait donner des indications concernant l'intérêt et l'importance de chaque nom cité.

Signalons alors qu'un phénomène de transcription est observable tout en utilisant un alphabet différent. Ce phénomène, le plus fréquent dans la majorité de notre corpus, est observé April 2016 
pour tous les noms propres du texte lors de leur transfert du texte français en arabe. Ce phénomène se retrouve en arabe où le nom propre subit un phénomène d'adaptation phonétique ou graphique, ce qui permet l'adaptation de ceux-ci aux différentes exigences orthographiques de l'arabe tout en respectant la prononciation locale du nom propre.

\subsection{Fautes de traduction}

Afin de bien traduire, il faut couramment avoir les deux langues, travailler davantage et de faire plus attention. C'est la raison pour laquelle il faut profiter des stratégies et des procédés de la traduction. Le délicat travail de Salam et de Tayar est sujet à quelques controverses. Nous trouvons quelquefois des malformations, des erreurs et des défauts. Notre travail ne consiste pas à critiquer leur tentative de traduction. Notre étude porte essentiellement sur l'affrontement de deux traductions pour voir le degré de précision entre le français et l'arabe. De là, nous insistons sur certaines fautes très fréquentes de traduction faites par les deux traducteurs. Ladmiral a tenté de distinguer les différentes fautes de traduction "Quant au faux sens, on voit souvent en lui un contre-sens au petit pied [...] D'une façon plus systématique, on pourra distinguer deux grands types de fautes : d'une part la triade non-sens/contre-sens/faux sens, où les fautes sont des erreurs d'interprétation portant sur la signification même du texte, et d'autre part un nuage de fautes plus minimes qui sont des fautes de français, portant sur la structuration terminale du signifiant-cible [...] Le faux sens ressortit à un problème d'expression en français langue-cible maternelle (L1), le contre-sens à la compréhension du texte-source... ${ }^{I}$ ». Nous insistons sur la triade non-sens/contre-sens/faux sens

1 ) LADMIRAL, J.-R. Traduire : Théorèmes pour la traduction, op.cit, p. 62 April 2016 


\subsubsection{Faux-sens}

Le faux sens consiste à prendre un mot pour un autre. $\mathrm{Ou}$ bien, c'est une "faute de traduction qui consiste à attribuer à un mot ou à une expression du texte de départ une acception erronée qui altère le sens du texte, sans pour autant conduire à un contresens [...] Le faux sens résulte habituellement de l'appréciation erronée de la (signification pertinente) d'un mot. Ce glissement de sens dî̀ à une interprétation fautive conduit généralement à une (impropriété) [...] Le faux sens est une erreur moins grave qu'un contresens ou un non-sens, car il ne dénature pas complètement le sens du texte de départ. Néanmoins, la ligne de démarcation entre le faux sens et le contresens est parfois difficile à tracer ${ }^{I} »$. Tout simplement, nous disons le faux sens existe quand la traduction n'est pas juste.

Voilà des exemples pris du poème «Bénédiction » :

\begin{tabular}{|r|r|}
\hline \multicolumn{2}{|c|}{ Baudelaire : des ceurs illustres, } \\
\hline سلام : الطيار: القلوب مبرقة الكبيرة \\
\hline
\end{tabular}

En ce qui concerne la version donnée par Al-Tayar, elle semble contenir des faux sens. Sur le plan sémantique, les

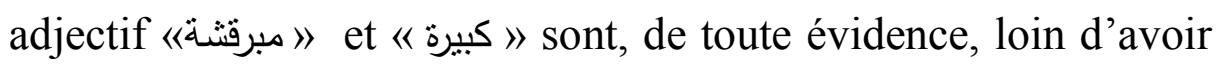
le même sens. Le terme "الكبيرة " se traduit en français par " grand 》, tandis que l'adjectif 《مبرقتش 》 se rend par «bariolé 》, c'est-à-dire composé de couleurs vives et variées. Il est important que l'idée de l'original et le vouloir dire sont fidèlement rendus et exprimés dans la langue cible. Etant donné que le terme «illustre» signifie : Qui s'est acquis la renommée, la célébrité ou

1 ) DELISLE et al. Terminologie de la traduction, op.cit, p. 40 
La traduction poétique entre la littéralité et l'adaptation Dr.Magdi Adli Ahmed

la gloire par ses action ${ }^{l}$, il peut être rendu en arabe par "لامع 》. Sallam, de sa part, a employé un mot voisin pour rendre le sens 《مبرقشة). Al-Tayar semble qu'il n'a pas bien compris l'idée de l'original et a ajouté un élément qui n'a rien à voir avec la conception du poème. Sa traduction 《كبيرة déforme le sens. Elle ne correspond pas exactement au texte source.

Une pareille dissemblance sémantique entre le texte source et la traduction se manifeste à cet exemple du poème «Bénédiction» :

Baudelaire : Où ne mordront jamais la terre et les enfers جحيم الطيار :الذي لا نرقى إليه أرض ولا

Il est judicieux de remarquer qu'Al-Tayar a tort en traduisant le verbe 《mordre»par "نرقى 》. Le traducteur comprend le sens du mot, mais il n'arrive pas à comprendre l'idée que le poète veut dire. Sa traduction n'est pas juste. C'est une mauvaise appréciation du mot traduit. C'est la raison pour laquelle, nous préférons de dire " أكل - عض p pour bien rendre le sens du verbe. Alors, sa traduction dénature le message da la langue source. Par contre, Sallam a bien rendu le message original préférant la traduction littérale.

Voyons ces autres exemples de même poème :

\begin{tabular}{|c|c|}
\hline \multicolumn{2}{|c|}{ Baudelaire : les desseins éternels } \\
\hline الطيار : القدر المحتوم : الأقدار الأبدية المرسومة : & : الألام \\
\hline
\end{tabular}

1 ) http://www.larousse.fr/dictionnaires/francais/illustre/41580 
Dû à une interprétation fautive, la traduction du terme

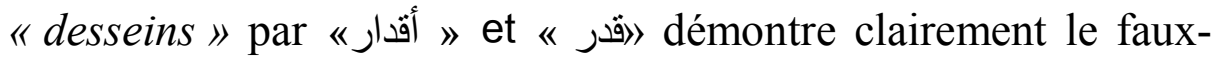
sens fait par les traducteurs. D'après les dictionnaires bilingues, le mot "desseins" porte une signification tout à fait différente

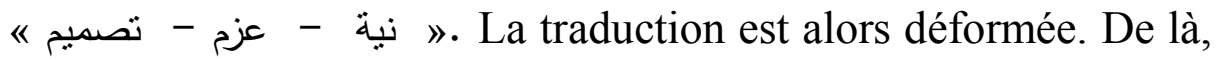
le faux-sens est dû au manque de connaître et de comprendre le message source. Nous proposons alors la traduction suivante: (النوايا الأبدية).

\begin{tabular}{|c|c|}
\hline \multicolumn{2}{|c|}{ Baudelaire : et s'enivre en chantant du chemin de la croix } \\
\hline سلام : & الطيار : \\
\hline ينتشي بالإنشاد لطريق الصليب & ويمشي على درب الآلام وهو يغني \\
\hline
\end{tabular}

Ces exemples témoignent des incohérences stylistiques de la traduction arabe. Chacun de deux traducteurs a commis une grave erreur conduite à nuire au sens. Bien que, la traduction effectuée par Sallam garde presque la même structure de la phrase originale, même du point de vue de l'ordre des mots, elle s'écarte de la version originale. Il ne bien comprend pas le message source. La version d'Al-Tayar est ainsi faux-sens. La traduction du verbe " S'enivre" par "يمشي" démontre que le traducteur a pris le chemin du faux-sens. Il a un sens intégralement différent "نتشى - سكر - ثمل " Également, les traducteurs ont trahi le sens. La traduction de l'expression «

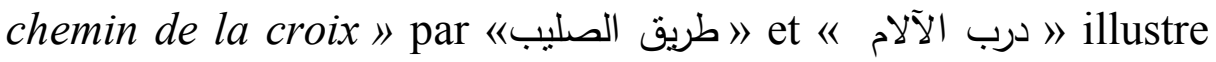
distinctement le faux-sens commis par les traducteurs, étant que la traduction appropriée est "مراحل الصلب". Le mauvais choix du mot découle évidemment d'une mauvaise compréhension.

Baudelaire : l'Esprit qui le suit dans son pèlerinage 
La traduction poétique entre la littéralité et l'adaptation Dr.Magdi Adli Ahmed الطيار: الروح التي ترافقه في حجه المقد | سلام : الروح التي تتبعه في طوافه

Le faux-sens est dans la traduction du syntagme nominal 《 son pèlerinage » par «وافه " طو "Bien que la bonne traduction est

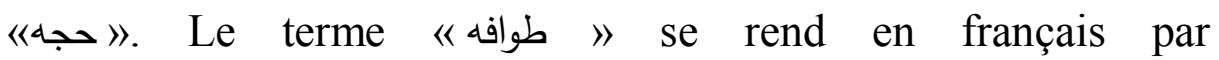
« circumambulation». En fait, il existe une grande différence entre les deux termes. Le طواف " حج) est l'un des piliers de. Il existe également un autre faux-sens dans la version d'Al-Tayar en rendant le verbe 《suit» par 《ترافقه qui a un sens différent 《ت نتبعه. Par conséquent, nous proposons la traduction suivante :

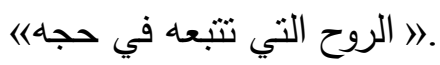

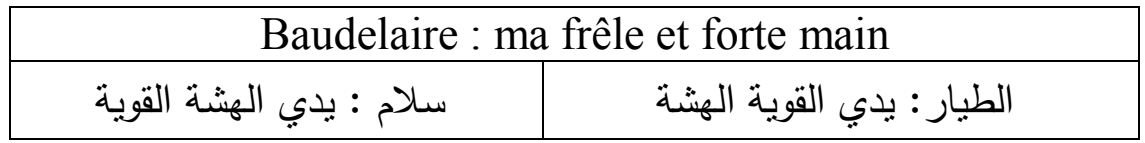

En raison de l'interprétation fautive, les deux traducteurs ont recours au faux-sens en employant les mêmes démarches pour rendre le message de la langue de départ, mais avec de différente attitude. La différence touche l'ordre des mots. Les traducteurs rendent l'adjectif «frêle 》 par un faux-sens 《شة ه. Son équivalent exact est "نحيفة 》. De là, les deux traducteurs portent atteinte au sens. Ils lui nuisent. Le faux-sens résulte de l'appréciation erronée de la signification pertinente du mot. La traduction proposée est alors : يدي النحيفة القوية 》.

\begin{tabular}{|l|l|}
\hline \multicolumn{3}{|c|}{ Baudelaire : pareils aux ongles des harpies } \\
\hline سلام: الثبيهة بأظافر الخفافيش الطبيار : الثبيهة ببرانس الجوارح \\
\hline
\end{tabular}


La traduction du syntagme nominal «des harpies » par 《الجوارح est un faux-sens qui rend la traduction inappropriée. Cette traduction nous semble, en fait, difficilement acceptable, mais, il est intéressant de noter qu'Al-Tayar a choisi le nom 《الجوارح》 plutôt que 《الخفافيش》). La déformation est due à la confusion d'Al-Tayar entre "الجوارح- Les oiseaux de proie» et 《الخفافش - les harpies». Ayant recours à la traduction mot à mot, Sallam fait un excellent passage de la langue française dans la langue arabe tout en faisant attention à ne pas perturber le texte original.

Analysons un autre exemple de choix erroné d'un terme pris du poème «Les Phares »

\begin{tabular}{|c|c|}
\hline Baudelaire : Goya, cauchema & plein de choses inconnues, \\
\hline سوبا، كابوس مليء بالأثنياء المجهولة & 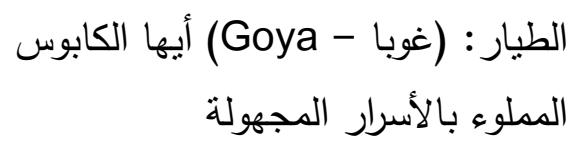 \\
\hline
\end{tabular}

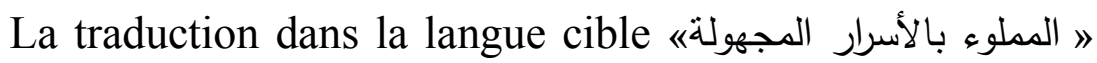
découle d'une mauvaise appréciation de l'énoncé dans la langue source. Il s'agit d'un faux sens composé par l'équivalence partielle de la langue source. L'équivalent français du terme 《أسرار, mal traduit, est «secrets ». De là, l'essai d'Al-Tayar n'est pas pertinente et significative. Sallam nous offre une belle traduction tout en gardant en général la même forme du texte source à travers le recours à la traduction littérale, mais cette traduction reste tout à fait compréhensible pour le lecteur arabe : elle est adéquate et précise : مليء بالأثياء المجهولة). 
La traduction poétique entre la littéralité et l'adaptation Dr.Magdi Adli Ahmed

Prenons à présent la traduction de ce vers du poème « $A u$ lecteur $\gg$ :

\begin{tabular}{|c|c|}
\hline Nos péchés sont têtus & repentirs sont lâches; \\
\hline سلام : خطايانا عنيدة وندمنا بليد & الطيار : آثامنا عنيدة وندمنا جبان \\
\hline
\end{tabular}

Remarquons que les adjectifs "têtus " et "lâches " sont antonymes. Les deux traducteurs ont rendu l'adjectif «têtus » par 《عنيدة). Mais, pour l'adjectif "lâches », chacun a opté une traduction différente. Sallam a choisi le terme 《بليد), tandis qu'Al-Tayar a utilisé le mot «بان》" C'est un faux-sens. La traduction mot à mot a amené les traducteurs à commettre une erreur fatale. Une traduction littérale de ces énoncés s'avère impossible. Les deux termes «têtus » et «lâches » sont employés dans un sens figuré. Afin d'aboutir à une traduction objective, ذنوبنا كثيرة وندمنا " : nous rendons cette phrase de la façon suivante

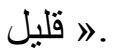

Voyons cet autre exemple tiré du même poème :

Que nous pressons bien fort comme une vieille orange.

الطيار : ونعتصرها عصر برثقالة ذابلة سلام: ونعتصرها بقوة كبرثقالة قديمة

La traduction mot à mot de l'adjectif 《 vieille 》 par 《ديمة 》 est un faux-sens. La_traduction n'est pas juste et pertinente. Sallam prend un mot pour un autre. La sensibilité de sa traduction est perdue. Il cherche cependant à maintenir le même mot de Baudelaire. C'est une mauvaise appréciation du sens d'un terme. Dû à la formation défectueuse du traducteur, il ne pourrait pas déceler le vouloir dire du poète. Elle le conduirait involontairement au faux-sens. "Une connaissance April 2016 
insuffisamment intuitive des langues a souvent pour effet de faire douter du niveau de traduction auquel il convient d'opérer ${ }^{l} \gg$. La traduction exacte et adéquate est celle d'Al-Tayar ذابلة " qui est plus harmonieuse avec le texte source.

Signalons alors que "Les fautes de sens sont dues à des lacunes dans la compétence en langue de départ, à une ignorance dans un domaine du savoir ou du comportement en société et à des illogismes ${ }^{2} »$.

\subsubsection{Contresens}

Le contresens aboutit à une traduction contraire de ce qui a été énoncé. D'après Delisle c'est une "faute de traduction qui consiste à attribuer à un segment du texte de départ un sens contraire à celui qu'a voulu exprimer l'auteur ${ }^{3}$ ». Il provient d'une erreur d'explication ou d'une insuffisance de culture générale et conduit à la trahison de la pensée du poète. Pour Le Petit Robert le contresens est une "interprétation contraire à la signification véritable. ${ }^{4}$ ». C'est à dire attribuer à un terme, à un groupe de terme ou à une expression un sens erroné.

Prenons ces exemples tirés du poème «Bénédiction » :

\begin{tabular}{|l|l|}
\hline \multicolumn{2}{|c|}{ Baudelaire : miroir profond et sombre, } \\
\hline الطيار : يا مرآة عميقة فاتحة : مرايا معتمة نائحة \\
\hline
\end{tabular}

Il est clair que nous trouvons toujours plusieurs traductions pour un même terme, mais il est impossible que toutes les

1) SELESKOVITCH D., \& LEDERER M., Interpréter pour traduire, Didier, Paris, 2001, p. 128

$\left.{ }^{2}\right)$ DUSSART, André, Faux sens, contresens, non-sens... un faux débat ? op.cit, p. 116

$\left.{ }^{3}\right)$ DELISLE et al. Terminologie de la traduction, op.cit, 1999, p. 23

$\left.{ }^{4}\right)$ REY A., Le Petit Robert, Robert, Paris, 2003, p.538 
La traduction poétique entre la littéralité et l'adaptation Dr.Magdi Adli Ahmed

traductions présentent la même fréquence d'utilisation. La version arabe d'Al-Tayar est un contresens. La traduction dans la langue cible «فاتحة) a un contresens par rapport à la langue originale «sombre ». C'est précisément l'inverse qu'il convient de faire. La traduction du terme découle d'une faute

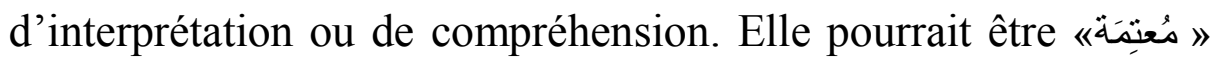
ou هُظظِلمَة comme l’a traduit Sallam.

\begin{tabular}{|l|l|}
\hline \multicolumn{2}{|c|}{ Baudelaire : les yeux mortels } \\
\hline سلام : العيون الفانية & : العيار : \\
\hline
\end{tabular}

La traduction opposée de l'expression de «les yeux mortels 》 par العيون الغافية pose la question du contresens. AlTayar a en effet pris un chemin tout à fait différent du texte

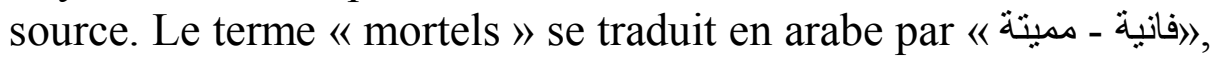
tandis que le terme 《غافية》 opté par Al-Tayar est rendu par

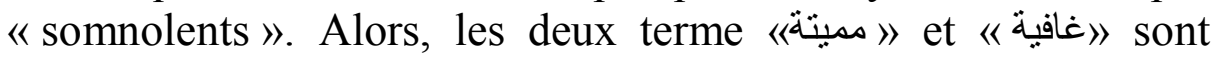
complètement opposés.

Prenons également cet exemple du poème «Au lecteur »

\begin{tabular}{|r|r|}
\hline \multicolumn{3}{|c|}{ Nous nous faisons payer grassement nos aveux، } \\
\hline ونحن ندفع غالياً ثن اعترافاتتا \\
\hline الطيار \\
\hline وندفع ثنا باهظا لاعترافاتا
\end{tabular}

La traduction de la tournure "Nous nous faisons payer "

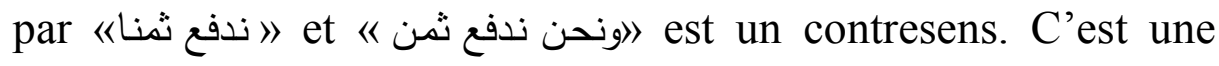
traduction irrecevable. Nous devons traduire le texte sans faire sciemment des contresens. La traduction poétique demande une attention singulière. Et comme «la traduction est un acte de 
communication»" le traducteur doit comprendre pour faire comprendre à son lecteur. Du à la mal compréhension du message source, les traducteurs prennent une voie très loin de l'original. En effet, il existe un très grand décalage entre "Nous nous faisons payer 》 et "Nous payer 》. La première se traduit par « نستقضي (نُدَفِعُ- نقبض) ثنا 》. Afin d'aboutir à une traduction objective, nous rendons cette phrase de la façon suivante : ونحن نقبض ثمنا باهظا

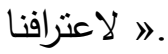

Prenons cet autre exemple du poème «Au lecteur $»$ :

\begin{tabular}{|c|c|}
\hline \multicolumn{2}{|c|}{ Quoiqu'il ne pousse ni grands gestes ni grands cris, } \\
\hline سلام : على الرغم انه لا يصدر حركات & الطيار : وهو، وإن كان قليل الحرالك \\
\hline واضحة، ولا صرخات فادحة & ضعيف الصوت \\
\hline
\end{tabular}

Les différentes traductions de ce vers ont fait surgir un contresens manifeste. La traduction du syntagme nominal

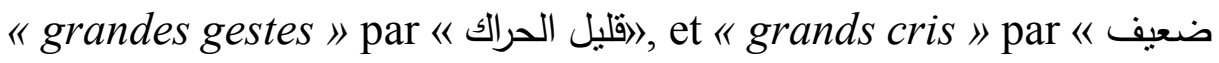
" الصوت est un contresens. Il établit une contradiction en traduction. Il existe en effet un contresens lorsque les deux langues sont opposées. De plus, la traduction du même syntagme, dans la version Sallam, par 《حركات واضحة et et "حرخات فادحة est un faux-sens. Nous voyons que toutes les deux traductions sont inappropriées. Raison pour laquelle, nous proposons la traduction suivante : إإثارات قوية وصرخات مدوية.

1 ) RICOEUR, Paul, sur la traduction, op.cit, p. 5 
A travers ces exemples, nous voyons que les traducteurs essayent d'être plus proche et très fidèle à l'original français, de transférer plus claires les idées du texte de départ et de rendre le texte plus accessible, plus familier, plus lisible et compréhensible.

\subsubsection{Non-sens}

Le non-sens est une "Faute de traduction qui consiste à attribuer à un segment du texte de départ un sens erroné qui a pour effet d'introduire dans le TA une formulation absurde ${ }^{1} »$. Il faut également ajouter que "le "nonsense " ne découle pas seulement d'une connaissance imparfaite de la langue source, mais plus souvent d'une maîtrise insuffisante des domaines de spécialité et qu'il s'observe chez des traducteurs s'exprimant très bien à la fois dans la langue de départ et dans la langue d'arrivée $e^{2} »$.

Prenons ces exemples du poème «Bénédiction » :

\begin{tabular}{|c|c|}
\hline \multicolumn{2}{|c|}{ Baudelaire : L'Enfant déshérité s'enivre de soleil, } \\
\hline سلام : يسكر الطفل المحروم بالثمس، & الطيار : . الولد المحروم فيسكر بالصفاء \\
\hline
\end{tabular}

Ces traductions ne donnent qu'une vague idée de 1'original. Elles n'ont plus aucun sens, elles deviennent absurdes, insignifiantes et insensées. Elles ne correspondent pas au texte original. Elles sont en effet dépourvues de sens. Le non-sens révélé ici survient sur toute la phrase traduite. Dû à la mauvaise interprétation du message source, la traduction en arabe est absurde ou incohérente, c'est-à-dire que le texte est complètement incompréhensible. En effet, le but de la traduction est de

\footnotetext{
1 ) DELISLE et al. Terminologie de la traduction, op.cit, p. 53

2 ) DUSSART, André, Faux sens, contresens, non-sens... un faux débat? op.cit, p. 114 April 2016 
transformer le texte source au texte cible en conservant toutes les valeurs sémantiques du texte source, et en se rendant compte des décalages existant entre la langue originale et la langue cible. De là, nous proposons la traduction suivante : " أصيب الولد السسكين

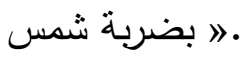

\begin{tabular}{|c|c|}
\hline Baudelaire : s'enhardiss & tranquillité, \\
\hline سلام : مجترئين على سكينته & الطيار : يغتتمون هدوءه \\
\hline
\end{tabular}

La traduction de Sallam n'est pas adéquate et insignifiante. Sallam a habituellement tendance à la littéralité qui quelquefois déforme le sens. Le traducteur doit renvoyer aux lecteurs, de la manière la plus fidèle possible, le message de l'auteur, y compris son intension esthétique. "L'cuvre littéraire n'est pas autre chose qu'une communication, et toute l'esthétique qu'y rentrer l'écrivain n'est en définitive qu'un moyen de gagner plus sûrement l'adhésion du lecteur ${ }^{I} »$. La version d'Al-Tayar est pertinente. Mais, nous pouvons reformuler sa traduction pour être plus précise. Nous disons ينتهزون لحظة هدوه " .

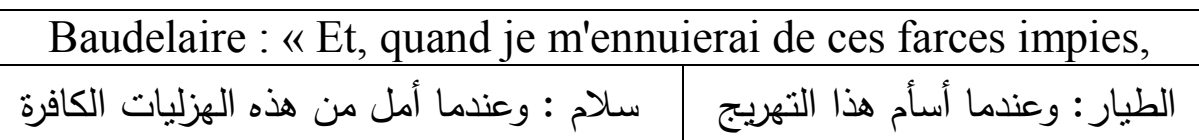

Si nous comparons les deux textes « source et cible», nous trouvons un sens confus à propos de "ces farces impies ", parce que l'idée essentielle n'est pas claire. La traduction de l'expression «ces farces impies》par 《الهزليات الكافرة démontre clairement le non-sens commis par le traducteur. Elle est en effet dépourvue de sens. La traduction d'Al-Tayar est donc meilleure

1 ) CRESSOT, M. : Le style et ses techniques, Précis d'analyse stylistique, PUF. Paris, 1947, p. 17 
du point de vue sémantique. Quand même, nous proposons cette tentative de traduire : "عندما أمل من هذا التهريج". L'effacement de l'adjectif «impies» ne déforme pas le sens; car le traducteur doit exprimer les termes qui s'accordent harmonieusement avec l'esprit du texte à traduire. Le style du texte traduit doit être pris en considération, et sa valeur esthétique doit être mise en évidence.

Voilà un autre exemple pris du poème «Les Phares » :

\begin{tabular}{|c|c|}
\hline \multicolumn{2}{|c|}{ Baudelaire : comme un soupir étouffé de Weber ; } \\
\hline سلام:متل تتهيدة مكتومة لفيير & الطيار :من زفرات الموسيقى وبيير(Weber) \\
\hline
\end{tabular}

Dans sa traduction, Al-Tayar évite la traduction littérale, mais en même temps, il ne s'éloigne pas beaucoup du texte original. La traduction dans la langue cible "من زفرات الموسيقى est inadéquate et insignifiante de même que les mots sont juxtaposés mais il n'existe pas de sens du point de vue de la culture de la langue cible. En fait, Al-Tayar a sciemment recours à la traduction interprétative qui nuit au sens. C'est une traduction intégralement dépourvue de sens. Pour éviter le non-sens, nous devons avoir recours au procédé d'équivalence pour obtenir une

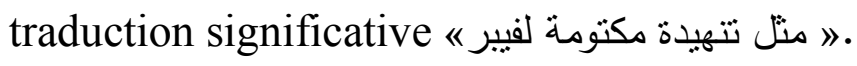

Pour évaluer la traduction, il est donc meilleur de favoriser les critères qui permettent d'envisager les côtés positifs de la traduction. Il faut éviter, autant que possible, la triade fauxsens/contresens/non-sens qui n'envisage que des fautes de traduction.

\section{Conclusion}


Compte tenu du décalage existant entre les deux langues, nous avons étudié deux traductions de quelques poèmes de Fleurs du Mal de Charles Baudelaire en arabe à partir d'une analyse comparative afin d'essayer de comprendre comment les traducteurs en question ont fait face aux difficultés de la traduction de la poésie et de voir à quel point ces deux traductions se rapprochent ou s'éloignent du texte source.

$\mathrm{Au}$ terme de cette étude, nous pouvons affirmer que la traduction poétique est certes une exercice difficile, mais non impossible, vu qu'elle a des caractéristiques spécifiques qui compliquent la traduction. Il s'agit d'un genre spécial et d'une capacité créatrice et esthétique. Le traducteur ne peut pas facilement transposer à la langue cible toutes les qualités de l'œuvre poétique, spécialement les rimes, les allitérations et les syllabes. De là, l'abandon de la rime dans la traduction en arabe de la poésie française paraît néanmoins acceptable. Nous ne pouvons pas conserver la régularité métrique du vers de Baudelaire. Il est incontestablement difficile de préserver la métrique, d'attribuer les rythmes adéquats à chacun des thèmes illustrés dans la poésie. Traduire un vers par un vers est une grande leurre et ne peut pas être transposé en pratique. Il est meilleur de transférer les poèmes par prose.

La littéralité et l'adaptation sont des caractéristiques essentielles de la traduction de la poésie de Baudelaire. Les traducteurs y ont énormément recours. La traduction est donc présente sous différentes formes.

Nous voyons que Sallam essaie d'être plus proche et très fidèle à l'original français. Dans la plus grande partie de sa traduction, il suit fidèlement le style de Baudelaire. Il nous donne une traduction entièrement littérale en suivant la même structure que la phrase française. Dans sa traduction, le respect de la 
strophe m'a paru indispensable Il cherche cependant à garder la même forme des vers sources. Il a préservé les caractéristiques des poèmes originaux, conservant le plan des strophes utilisé par Baudelaire.

Al-Tayar reste très proche du texte français. Il essaie de restituer tous les éléments, tout en utilisant souvent les vers libres, propre à son style qui est différent des caractéristiques du style de Baudelaire, il présente un style innovateur, sans règles établies. Également, sa traduction est presque interprétative et littérale à la fois. Ses phrases étaient plus longues en ayant recours à la redondance qui distingue la langue arabe. Quelquefois, sa traduction risque de s'éloigner un peu par rapport au texte de départ.

En général, chacun de deux traducteurs a présenté une traduction plus harmonieuse. Les traducteurs ne doivent pas se contenter de restituer littéralement la poésie, de la restituer librement. Ils doivent recréer et réécrire tout en prenant en considération que, comme le disait Mounin, "la traduction est un art, mais un art fondé sur une science ». Il convient plutôt de mettre en œuvre les stratégies les plus adaptées et de rendre les poèmes aussi bien de façon fidèle que re-créative. Ils ont recours à la traduction libre en employant certains procédés de traduction, tels que, la transposition, la modulation et l'inversion des mots pour bien rendre le message et respecter les particularités et les singularités de la langue arabe. De plus, l'ajout et l'omission sont couramment marqués dans les traductions des poèmes de Baudelaire. Les deux traducteurs étaient obligés quelquefois à renoncer et rajouter certains éléments inexistants dans le texte source. Ils devraient ajouter des mots significatifs pour préciser le sens de leur traduction quand cela est nécessaire. Ce sont presque des adjectifs, des conjonctions, des noms et des pronoms etc. Puisque, l'ajout est 
motivé par le besoin d'introduire dans la langue d'arrivée des précisions qui restent implicites dans la langue de départ. Mais, ils ont quelquefois introduit de façon non justifiée dans le texte d'arrivée des éléments d'information superflus.

Ils devraient également omettre des mots seulement quand ces termes ne sont pas indispensables pour la compréhension du message original. Mais, nous avons trouvé des omissions non justifiés. Parfois, ils n'ont pas rendu dans le texte d'arrivée un élément de sens du texte de départ sans raison valable.

Nous avons noté des fautes, parfois grossières, dû à l'incompréhension des traducteurs tels que : le faux-sens, le nonsens et le contresens.

Notre analyse a démontré que Sallam sait très bien la langue française et qu'il s'est présenté comme un excellent traducteur. Mais Al-Tayar s'est présenté aussi comme un bon connaisseur de la langue française. A notre avis, Sallam a produit un travail qui cherche vraiment à faire œuvre, tout en respectant l'esprit créateur de Baudelaire. Sa version restera éternellement une traduction de grande valeur qui aura une influence plus considérable sur la littérature arabe.

\section{Bibliographie}


La traduction poétique entre la littéralité et l'adaptation Dr.Magdi Adli Ahmed

\section{1-Corpus :}

Les fleurs du Mal de Charles Baudelaire :

http://www.ac-nice.fr/docazur/IMG/pdf/les fleurs du mal.pdf

http://samirwatfa.yoo7.com/t778- ترجمة حنا الطيار و جورجيت الطيار topic. 2009

\section{Références}

1. ALI, Magdi, les problèmes posés par la traduction en arabe du roman de Michel Tournier Vendredi ou la vie sauvage, thèse de Doctorat, université de Provence, Marseille, 2006

2. BLACHERE, R. Grammaire de l'arabe classique, Maisonneuve et Larousse, Paris, 1952

3. BONNEFOY, Yves, Les Poèmes (Vénus et Adonis, Le Viol de Lucrèce, Phénir et Colombe), Préface «Traduire en vers ou en prose ", Mercure de France, 1993.

4. BRAUNS, Jean, Comprendre pour traduire, perfectionnement linguistique en français, Maison du dictionnaire, Paris, 1981.

5. CARY, Edmond, "Traduction et poésie ", in: Babel : revue internationale de la traduction, Fédération internationale des traducteurs, 1957.

6. CELOT, Alberto, La traduction de l'essai poétique : domaine Français Italien. Linguistics. Université de la Sorbonne nouvelle Paris III, 2014.

7. CRISTA Teodora, stratégies de la traduction, Editura Fundaţiei România de Mâine, București, 2007. 
8. CRESSOT, M. : Le style et ses techniques, Précis d'analyse stylistique, PUF., Paris, 1947.

9. DARBELNET, Jean. Traduction littérale ou traduction libre ? in Meta : journal des traducteurs / Meta: Translators' Journal, vol. 15, $\mathrm{n}^{\circ} 2,1970$, p. 88-94.

10. Dictionnaire de Langue Française, encyclopédie et noms propres, Hachette, Paris, 1987

11. DELISLE, J., La traduction raisonnée, Presse de l'Université d'Ottawa, Ottawa, 1993.

12. DELISLE, J., LEE-JAHNKE, H. et CORMIER, M. C. Terminologie de la traduction, Philadelphia, John Benjamins coll., Amsterdam, 1999.

13. DUSSART, André, Faux sens, contresens, non-sens... un faux débat ? Meta: journal des traducteurs, vol. 50, $\mathrm{n}^{\circ} 1,2005$

14. ELLRODT, Robert, "Comment traduire la poésie ?", Palimpsestes [En ligne], 2006, URL : http://palimpsestes.revues.org/247

15. GILE, Daniel, La traduction, la comprendre, l'apprendre, PUF., Paris 2005

16. GREENSTEIN E. L., Essays on biblical method and translation, Scholars Press, Atlanta, 1989.

17. GUIDERE, Mathieu, La traduction arabe, Méthodes et applications, Ellipses, Paris, 2005.

18. HURTADO, Albir Amparo, La notion de fidélité en traduction, Didier Erudition, Paris, 1990. 
La traduction poétique entre la littéralité et l'adaptation Dr.Magdi Adli Ahmed

19. LADMIRAL, Jean René. Traduire, théorèmes pour la traduction, Gallimard, Paris, 1979.

20. LEDERER, M. La traduction aujourd'hui, le modèle interprétatif, Hachette, Paris, 1994.

21. LEDERER, Marianne, études traductologiques, textes réunis, lettres moderne minard, Paris, 1990.

22. LUNGU BADEA, Georgiana, Sur la fragilité des signes. Diverses questions sur la traduction de poésie, URL : http://www.uab.ro/reviste recunoscute/philologica/philologica 20 05 tom2/39.doc

23. MALBLANC, A., Stylistique comparée du français et de l'allemand, Essai de représentation linguistique comparée et Etude de traduction, Didier, Paris, 1968

24. MAXIME, Lecture analytique d'Harmonie du soir de Charles Baudelaire, URL : http://lectureanalytique.over-blog.com/article35707592.html.

25. MESCHONNIC, Henri, Poétique du traduire, Editions du Verdier, 1999.

26. MICLAU, Paul, Signes poétiques, Editura Didactică şi Pedagogică, Bucureşti, 1983.

27. MICHEL, Jacqueline, les enjeux de la traduction littéraires, textes réunis, Publiesud, Paris 2004.

28. MONTEIL, Vincent, l'arabe moderne, Klincksieck, Paris, 1960

29. MOUNIN, Georges, Les problèmes théoriques de la traduction, Gallimard, Paris, 1963. 
Benha University Journal of Faculty of Arts

30. OSEKI-DÉPRÉ, Ines, Traduction et poésie, Maisonneuve\& Larose, Paris, 2004.

31. PLACIAL, Claire, "Seul un poète peut traduire la poésie " Vraiment? URL: http://languesdefeu.hypotheses.org/814

32. REY, A. et REY-DEBOVE J., Le Grand Robert de la langue francaise, Robert, Paris, 2001.

33. REY, A, Le Petit Robert des noms propres, Robert ED LE, Paris, 2003

34. RICOEUR, Paul, sur la traduction, Bayard, Paris, 2004.

35. RIEGEL, Martin. Les opérations linguistiques de base (suite) : L'effacement et l'addition. In: L'Information Grammaticale, N. 16, 1983. URL: http://www.persee.fr/doc/igram 022298381983 num $16 \quad 1 \quad 2317$

36. SELESKOVITCH D., \& LEDERER M., Interpréter pour traduire. Didier, Paris, 2001

37. SOBHY, Camélia, La traduction $d u$ nom propre, URL: http://www.atida.org/french/index.php?option=com content\&vie $\underline{w}=$ article\&id $=4:$ la-traduction-d

38. TATILON, Claude, Traduire: Pour une pédagogie de la traduction, Editions du Gref, Toronto, 1986.

39. VINAY, J.-P., et DARBELNET J., Stylistique comparée du français et de l'anglais, méthode de traduction, Didier, Paris, (1978) [1958].

\section{3-Sitographies}

1. http://www.bacfrancais.com/bac francais/68-commentairebaudelaire-les-phares.php 
La traduction poétique entre la littéralité et l'adaptation Dr.Magdi Adli Ahmed

2.http://analyses-

litteraires.com/analyses/viewtopic.php? $\mathrm{f}=364 \& \mathrm{t}=589 \&$ start $=1 \& s t$ $=0 \quad \&$ sk $=$ t\&sd $\quad=\quad$ a

\&sid=9ade8319c6bdd2f9ca2a80135ce20427\&view=print.

3. https://fr.wiktionary.org/wiki/travailler

4. http://fr.wiktionary.org/wiki/dérision

5.

http://www.larousse.fr/dictionnaires/francais/d\%C3\%A9rision/24 $\underline{015}$

6.

http://www.almaany.com/ar/dict/ar-

ar/\%D9\%85\%D8\%B3\%D8\%AE/

$7 . \quad$ http://dictionnaire.reverso.net/francais-

definition/noeud $\% 20 \mathrm{de} \% 20 \mathrm{vip} \% \mathrm{C3} \%$ A8res

8. http://www.notrefamille.com/dictionnaire/expression/vipere

9. http://www.larousse.fr/dictionnaires/francais/saint sainte/70547 10http://www.larousse.fr/dictionnaires/francais/sacr\%C3\%A9/70 445?q=sacr\%C3\%A9\#69689

11. http://www.croire.com/Definitions/Ecole-de-priere/Chemin-decroix

12.http://www.larousse.fr/dictionnaires/francais/chemin/15074/loc ution?q=chemin+de+croix $\# 152635$;

13. http://www.larousse.fr/dictionnaires/francais/noblesse/54726

14. http://www.larousse.fr/dictionnaires/francais/illustre/41580

15. https://fr.wiktionary.org/wiki/Hercule

16.

http://dicocitations.lemonde.fr/definition littre/12960/Hercule.php 